Switzer-Land of Opportunity:

Intergenerational Income Mobility in the Land of Vocational Education

Patrick Chuard and Veronica Grassi

July 2020 Discussion Paper no. 2020-11

School of Economics and Political Science, 


$\begin{array}{ll}\text { Editor: } & \text { Vanessa Pischulti } \\ & \text { University of St.Gallen } \\ & \text { School of Economics and Political Science } \\ & \text { Department of Economics } \\ & \text { Müller-Friedberg-Strasse 6/8 } \\ & \text { CH-9000 St.Gallen } \\ & \text { Phone +4171 224 23 07 } \\ & \text { Email seps@unisg.ch } \\ & \text { School of Economics and Political Science } \\ & \text { Department of Economics } \\ & \text { University of St.Gallen } \\ \text { Publisher: } & \text { Müller-Friedberg-Strasse 6/8 } \\ & \text { CH-9000 St.Gallen } \\ & \text { Phone +41 71 224 23 07 } \\ & \text { http://www.seps.unisg.ch }\end{array}$




\section{Switzer-Land of Opportunity:}

Intergenerational Income Mobility in the Land of Vocational Education ${ }^{1}$

Patrick Chuard and Veronica Grassi

Author's address:

Patrick Chuard-Keller, M.A.

Swiss Institute for Empirical Economic Research (SEW)

Univesity of St.Gallen

Varnbüelstrasse 14

$\mathrm{CH}-9000$ St.Gallen

Phone +41712242984

Email patrick.chuard@unisg.ch

Website www.sew.unisg.ch

Veronica Grassi, M.Sc.

Swiss Institute for Empirical Economic Research (SEW)

University of St.Gallen

Varnbüelstrasse 14

$\mathrm{CH}-9000$ St.Gallen

Phone +41712242871

Email veronica.grassi@unisg.ch

Website www.sew.unisg.ch

\footnotetext{
${ }^{1}$ We thank Monika Bütler, Dominik Ullmann, Caroline Chuard, and Urs Birchler for their support and advice.
} 


\begin{abstract}
This paper documents intergenerational income mobility in Switzerland. We use a unique administrative data set which links the universe of labor incomes since 1982 over generations and is matched to census and survey data. We find that relative income mobility in terms of rank-rank slope (0.15) is substantially higher than in the US and even higher than in Sweden. At the same time, we find that (academic) educational mobility is low. This shows that high income mobility can be achieved even without high educational mobility. However, to reach the top from the bottom («American Dream»), academic education is still key: Children from the bottom quintile who went to gymnasium or got a master's degree are more likely to reach the top quintile compared to their peers in the vocational education track. Looking at regional variation in mobility, we find lower absolute, but higher relative mobility in French- and Italiancompared to German-speaking areas.
\end{abstract}

\title{
Keywords
}

Social mobility, intergenerational income mobility, inequality

\section{JEL Classification}

$\mathrm{H} 31, \mathrm{~J} 13$ 


\section{Introduction}

Inequality is one of the primary policy concerns nowadays. Since the late 1980s, income and wealth inequality has increased in most Western countries (Alvaredo et al., 2017). This allegedly gave rise to populist parties and polarization. Nowadays, most people acknowledge that too much of inequality is a concern. It is, however, less clear what the optimal amount of inequality in a society is.

While the desired amount of inequality differs along the political spectrum, the notion that «every child should have the same chance to succeed» seems to be the common denominator along all parties. The American Dream is a moral foundation on which most Western societies are built. But upward mobility is not only morally desirable, it also matters for economic growth. Economic growth can suffer when children from poor parents are hampered to live up to their economic potential - a phenomenon called «Lost Einsteins» (Bell et al., 2019).

Despite its importance, only few studies have reliably estimated intergenerational mobility. This is because of the demanding data requirements: To minimize bias, longitudinal income data and information on parent-child relationships is required. In recent years, some notable exceptions succeeded to analyze such high quality data, for example Chetty et al. (2014a), Heidrich (2017), and Acciari et al. (2019).

In this paper, we study intergenerational income mobility in Switzerland. We use administrative high quality data, which cover the universe of all labor incomes between 1982 and 2017, and administrative linkages between parents and children. We provide national mobility estimates for country bench-marking and we analyze variation across regions. Using a rich set of covariates, we identify predictors of upward mobility. Particularly, we analyze how upward mobility and education relate to each other.

Switzerland is an interesting case to measure intergenerational mobility for several reasons. The foremost reason is its strong vocational education system with its unknown impact on intergenerational mobility. So far, no study has been conducted to estimate in- 
tergenerational mobility with high quality data in a country with a prominent vocational education system. Furthermore, Switzerland's labor market is interesting, as it is one of the most liberal in Europe. At the same time, Switzerland offers a generous welfare system. Those defining features of the Swiss labor market could influence intergenerational mobility in opposing ways. Therefore, intergenerational mobility for Switzerland can neither be inferred from Nordic countries, nor from the US.

Studying variation in mobility within Switzerland can help to advance the literature on intergenerational mobility in several ways. First, Switzerland is organized federally and comprises 26 cantons. Cantons have substantial authority in their policy shaping. This element allows to shed light on the effect of policies on mobility in quasi-experimental settings. Second, Switzerland is a multi-linguistic country. It inhabits the language border between two large cultural groups in Europe: the German and the Latin group.

Our study contributes to the literature in several ways. We are first to provide reliable estimates on intergenerational mobility for a country with a strong vocational education system — which could be a driver of upward mobility. Importantly, our data allows us to link information about an individual's education directly to individual mobility. Previous studies could only link educational differences on an aggregate level. Second, we add an interesting data point on intergenerational mobility for country comparison. This data point is interesting because Switzerland differs greatly from countries for which recent high quality estimates exist (such as Italy, the US, or Sweden). Third, using a rich set of individual covariates, we can identify factors that correlate with upward mobility. Those covariates give research hinges on drivers of upward mobility.

We find that intergenerational income mobility is high in Switzerland. A child with a father in the highest income rank 100 can expect to achieve rank 57 ( $\approx 68,000 \mathrm{CHF}$ ), whereas a child with a father from the lowest rank 1 can expect to achieve rank $42(\approx$ 56,000 CHF). ${ }^{1}$ This difference of 15 ranks translates on average to roughly 12,000 CHF,

\footnotetext{
${ }^{1}$ It is important to mention that there is a large difference between incomes of daughters and sons. Sons from fathers in the highest percentile can expect to achieve rank 68 ( $\approx 76,000 \mathrm{CHF}$ ), sons from fathers in the lowest percentile can expect to achieve rank $53(\approx 65,000 \mathrm{CHF})$. Daughters from fathers
} 
which corresponds to around two median monthly salaries in Switzerland. This difference in ranks is lower than in Sweden with 18 ranks, Italy with 25 ranks and much lower than in the US with 34 ranks (Heidrich, 2017; Chetty et al., 2014b; Acciari et al., 2019).

Interestingly, we find that educational mobility is low — despite the high income mobility estimates. Less than $10 \%$ of the children with a father below the median income get a master's degree. In contrast, this share is almost $40 \%$ for children with a father higher than rank 90. Those results are quite captivating. They show that educational mobility — in the sense of academic education — is no prerequisite for income mobility. One way to explain this finding is that the Swiss education system is permeable. Our analysis shows that even after vocational education, around $40 \%$ receive some sort of tertiary education.

Further, we find that absolute mobility differs between regions in Switzerland. For example, a child born with a father at rank 25 of the national income distribution can expect to make it to rank 50 in the canton of «Zug», but only to rank 42 if born in the canton of «Basel Stadt». Additionally, we find lower absolute mobility in the French part of Switzerland compared to the German part.

We structure this paper as follows. First, we summarize the literature on intergenerational mobility. Then, we outline the different measures to estimate mobility and describe our sample. Next, we present the results on a national level and compare them to other countries. Then we analyze how education depends on parental income. In the next section, we look at regional variation within Switzerland. After, we analyze correlates of intergenerational mobility on a regional and individual level. In the robustness section, we show that our results are robust to several specifications. The last chapter discusses the results and compares. ${ }^{2}$

in the highest percentile can expect to achieve rank $46(\approx 60,000 \mathrm{CHF})$, while daughters from fathers in the lowest percentile can expect to achieve rank 30.5 ( $\simeq 43,000 \mathrm{CHF}$ ). Compare Figure A2, Panel (b).

${ }^{2}$ Throughout this study, the term intergenerational mobility or mobility will refer to income mobility across generations - if not stated otherwise. 


\section{Literature}

This study builds on the literature on intergenerational mobility. Since the pioneer contribution of Solon (1992), several scholars have analyzed income mobility across generations (see Solon (1999) and Black and Devereux (2011) for a review). Most of those studies relied on small-scale survey data and are therefore prone to several biases (e.g. sample selection, attenuation and life-cycle bias). Virtually all of those former studies estimate income mobility at the country level. Research on regional variation or on the determinants of income mobility is rare. This is likely because data requirement is demanding.

In the recent years, researchers gained access to extensive databases. The empirical literature on intergenerational income mobility has experienced a renewal and several studies explore income mobility within a country.

In the United States, Chetty et al. (2014a) uses tax data to provide a set of new and traditional measures of relative and absolute income mobility. Their results show large geographical variation in mobility across commuting zones. For example, the probability that a child from a family in the bottom quintile reaches the top quintile is $4.5 \%$ in Atlanta, while it is over two times higher in Washington. The study examines which socioeconomic factors drive the spatial variation. They find that upward mobility correlates with family structure, income inequality, segregation, and school quality. In contrast, factors such as tax policies, labor market conditions, migration or access to higher education correlate only weakly with upward mobility.

Heidrich (2017) analyzes income mobility in and across Sweden. She uses register data to estimate different measures of income transmission. Her results show that income persistence in Sweden is lower than in the United States. She associates a 10 percentile point increase in the parent rank with a 2 percentile increase in child rank. Her results show that relative mobility is quite homogeneous across regions, while absolute mobility differs more.

To learn about intergenerational income mobility in Italy, Acciari et al. (2019) make 
use of a large administrative tax data. The authors provide measures of relative and absolute income mobility. Upward mobility is higher in Italy than in the United States, but lower than in Nordic countries. Their study show substantial divergences in absolute and relative mobility across Italian provinces. The results from the correlation analysis shows that local labor market conditions, family stability, and school quality are the leading drivers of income mobility in Italy.

Despite a considerable literature, only few countries have credible estimates on intergenerational income mobility. So far, Switzerland has not been part of those countries. To the best of our knowledge, no previous study has analyzed income mobility across generations using high quality administrative data in Switzerland.

In a former study, Bauer (2006) looks at intergenerational income mobility in Switzerland. He estimates an intergenerational income elasticity (IGE) of 0.35 . This would mean that an increase by $1 \%$ in the parent's income is associated with an increase of $0.35 \%$ in the child income. However, the results from this study have to be interpreted with caution, as they are based on predicted incomes from a small-scale survey. The authors use data from the Swiss Household Panel, a survey that does not contain direct information on father's income. Small-scale surveys are prone to several biases and thus unlikely to provide unbiased estimates. In a recent study, Favre et al. (2018) use historical data from the City of Zurich and, examine the extent of occupational persistence during the 1780s and 1870s. Unexpectedly, their results show a decrease in occupational mobility. To summarize, no reliable information on intergenerational income mobility in recent years has existed for Switzerland. In a survey on wealth and income inequality in Switzerland, Föllmi and Martínez (2017) also note that studies on intergeneratinal mobility are missing due to lack of data.

We aim to fill the gap in the literature by providing the first estimate on intergenerational mobility for Switzerland based on administrative data. Thus, we add a further data point to the small set of reliable country estimates for international comparison. Our data has the advantage that we can directly identify a large share of family relationships from 
census data. In the studies from the US and Italy, children and parents can only be linked if a parents claim their children as dependent to get tax deduction. Furthermore, our data allows to directly link individual characteristics, such as education, religion or family characteristics. Previous studies mostly used regionally aggregated covariates for a correlation analysis. To sum up, we add to the literature not only by providing a country estimate but also by describing determinants of mobility.

\section{Measuring Intergenerational Mobility}

Income mobility aims to describe how a child's income depends on parent's income. In this section we describe the measures of income mobility we will use through the paper. We largely follow the previous literature, specifically Chetty et al. (2014a). This is to ensure that we can compare our estimates to those of other countries.

It is important to distinguish between two concepts of intergenerational income mobility: relative mobility and absolute mobility. Relative mobility captures the idea that all children should have equal opportunities to succeed - independent of the economic status of their parents. Absolute mobility measures where children end up in the income distribution, when they come from a specific parent rank. Usually, one is interested in the economic outcome of children coming from low income parents.

\subsection{Relative Income Mobility}

Relative mobility has been the focus of most prior work. It aims to answer the following question: «To which extent does my income depend on my parent's position in the income distribution?» In a society with perfect equality of opportunities, the relative ranking of parent's and children's income should be uncorrelated - assuming that genetic dispositions in ability are uncorrelated to a parent's income.

Relative upward mobility occurs when children increase their position in the income 
distribution compared to their parents. However, if someone moves up in relative terms, someone has to move down. When comparing relative mobility between units, higher relative mobility could also happen if children from rich parents do worse. Similarly, if all children increase their income compared to their parents in such a way that the income ranking stays constant, relative income mobility does not increase. Thus, the impact of changes in relative mobility on welfare is ambiguous.

We use two statistics to summarize relative income mobility: The more traditional «intergenerational income elasticity (IGE)» and the more recent «rank-rank slope (RRS)»:

\section{Intergenerational Income Elasticity (IGE)}

Intergenerational Income Elasticity (IGE) has been the most used measure for income mobility, probably because of its intuitive appeal. The IGE is estimated by regressing the logarithm of child income $\log \left(Y_{c}\right)$ on the logarithm of parent (usually father or family) income $\log \left(Y_{f}\right)$ :

$$
\log \left(Y_{c}\right)=\alpha+\beta \log \left(Y_{f}\right)+\epsilon
$$

The IGE results from Equation 1 as the estimated coefficient $\hat{\beta}$ :

$$
I G E=\hat{\beta}=\rho_{Y_{c} Y_{f}} \frac{S D\left(\log Y_{c}\right)}{S D\left(\log Y_{f}\right)}
$$

where $\rho_{Y_{c} Y_{f}}$ is the correlation between the logarithm of child income and the logarithm of parent income. $S D$ is the standard deviation.

The IGE measure the differences in income between children from high-income families versus children from low-income families. Thus, it captures the rate of regression to the mean. An IGE of 0.4 means that if parents earn $10 \%$ more, the income of their children is $4 \%$ higher. 
The intuitive approach of the IGE comes with some drawbacks. The IGE does not only capture the parent child relationship. Equation 2 shows that higher inequality in parent's income can lead to higher $S D\left(\log Y_{f}\right)$ and thus to a lower $I G E$. The most important drawback is that the relationship between log incomes of parents and log incomes of children is not well approximated by a linear regression. As a result the elasticity might not reflect income mobility at all points of the distribution. A further problem when estimating the IGE is the handling of zeros because the logarithm of zero is not defined. Dropping zeros can lead to overestimated mobility if observations with zeros are more prevalent within children of low-income parents.

\section{Rank-Rank Slope (RRS)}

Despite the shortcomings of the IGE, a parsimonious statistic facilitates the comparison of intergenerational mobility estimates between units (Black and Devereux, 2011). Another parsimonious statistic is the rank-rank slope $(R R S)$. It gained attention in recent years because it overcomes several drawbacks of the IGE. The rank-rank slope is a positional measure: Income of parents and children are transformed into their percentile ranks. Then, child income rank is regressed on parent income rank. The estimated slope of the linear regression is called the rank-rank slope (RRS).

$$
R_{i}^{c}=\zeta+\omega P_{i}^{c}+\pi_{i}^{c}
$$

where $R_{i}^{c}$ is the child rank in the income distribution of child cohort $c$ and $P_{i}^{c}$ is the parent's rank in the income distribution of child cohort $c$.

The estimated coefficient $\hat{\omega}$ yields:

$$
R R S=\hat{\omega}=\rho_{R_{i}^{c} P_{i}^{c}}
$$

The rank-rank slope measures the correlation between a child's position and its parent's 
position in the income distribution. The values range between zero and one. Values close to one indicate a society in which chance of succeeding depends highly on parent's rank. Values close to zero denote a society with low persistence. The slope $\hat{\omega} \times 100$ equals the child rank difference between children from the richest and lowest parent income percentile. This can be seen as the income wedge between rich and poor children.

Compared to the IGE, the RRS has several advantages. First, zero incomes are preserved. Second, previous studies using rank-rank measures have discovered a strikingly linear functional form (Chetty et al., 2014a; Dahl and DeLeire, 2008; Heidrich, 2017; Acciari et al., 2019). Furthermore, the transformation leads to the same standard deviation for parent and child income (both have a uniform distribution). This makes the RRS independent of changes in inequality between parents and children. ${ }^{3}$

\subsection{Absolute Income Mobility}

Another way to measure income mobility is to ask: «What are the outcomes of children from families at a given income or rank in the parental income distribution?» As explained above, relative mobility is not necessarily informative to capture the opportunities of poor children. Relative mobility can also be high when all children have the same low income or if rich children do worse. From a normative perspective, absolute mobility might therefore be more meaningful than relative mobility. On a binary scale, absolute income mobility increases if children earn more than their parents in real terms. This measure takes economic growth into account. If income grows for all children, absolute mobility happens, even though children from low-income parents still do worse than the ones from rich parents. Essentially: In contrast to relative mobility, absolute upward mobility does not mean, that if someone moves up, someone has to move down.

\footnotetext{
${ }^{3}$ With growing inequality the distance between the ranks is larger. If children move one rank down, this corresponds to a larger income loss in absolute terms.
} 


\section{Rate of Absolute Mobility (RAM)}

There are several statistics for absolute mobility. Absolute mobility can be analyzed for the whole society. Thereby, we estimate the share of children doing better than their parents in terms of income. The rate of absolute mobility (RAM) $A^{c}$ measures the fraction of children who earn more than their parents at the same age in real monetary units.

$$
A^{c}=\frac{1}{N_{c}} \sum_{i}^{N_{c}} 1\left[Y_{i}^{c} \geq X_{i}^{c}\right]
$$

$N^{c}$ is the number of children in the respective cohort. Incomes of parents and children have to be adjusted for inflation. Besides, income is usually measured around the age of 35 with the intention to approximate life-time income. We look at age 35 and 40 and compare gender-groups to each other (son-father, daughter-father, daughter-mother and son-mother).

\section{Absolute Upward Mobility (AUM)}

Absolute mobility can also be used to analyze subgroups of the population. For example, one might ask: «What is the income that children from poor parents can expect?» This is called absolute upward mobility (AUM). Following Chetty et al. (2014a), we define AUM as the mean adult rank of children whose parents were located at a the 25 th percentile in the parent income distribution.

When looking at large sample, specifically at the national level, AUM can inferred nonparametrically by simply calculating the mean rank of children with parents at rank 25. However, for smaller samples, e.g. at the regional level, noise might distort the measure and this estimate at precisely that point. Therefore, we use a statistical model to increase stability of the estimate. This statistical model is again the linear rank-rank regression. Instead of using the observed rank at parents rank 25, we use the rank that our linear model predicts. This is a reliable prediction because the rank-rank relationship is astonishingly well approximated by a linear model. 
AUM for small samples is calculated as the prediction of Equation 3 by using the estimated slope and intercept:

$$
\bar{R}_{p=25}^{c}=\hat{\zeta}+\hat{\omega} \times 25
$$

After the estimation, the expected rank $\bar{R}_{p=25}^{c}$ can be transformed back in absolute Swiss Francs to provide a more intuitive estimate. Thus, we know how much income a child from parents at the 25 th percentile can expect. Because the relationship is linear, the mean child outcome at the 25th percentile of parent's income, is the same as the mean outcome for parent's below the median. That is, the AUM measures the mean outcome of children born in the poorer half of the society.

The AUM is especially useful to compare regions to each other. Thus, the AUM answers in which areas children from poor parents can expect the highest income. Importantly,also when looking at regional estimates the income rank corresponds is defined in terms of the national income distribution. When looking at a subset of children, e.g. from a certain region or with certain characteristics, the rank-rank measures can also be used as an absolute measure. The idea is that changes in the subset do not impact the national distribution (Chetty et al., 2014a).

\section{American Dream Measure (Q1Q5)}

The last statistic we use is the American Dream (Q1Q5) measure (Chetty et al., 2014a). It describes the probability of a child born to parents in the bottom quintile to move up in the top quintile (Corak and Heisz, 1999; Hertz, 2006).

$$
Q 1 Q 5=\operatorname{Pr}\left[R_{c} \geq 80 \mid R_{f}<20\right]
$$

The quintiles are defined relative to the national income distribution. On a regional level, it serves as as an absolute mobility measure, because small areas are unlikely to affect the 
national distribution. We will use to this measure to analyse the determinants of upward mobility.

\section{Data and Variable Construction}

In this section, we first describe the data. Then, we explain how we construct variables to minimize life-time and attenuation bias. Finally, we provide summary statistics on the sample used in the analysis and show that it is representative for the whole country.

\subsection{Data Set}

Our main data results from a merge between three data sets: Income data, census data, and survey data.

\section{Income}

Our analysis is based on individual labor income data from the «social security earnings record» (SSER). The purpose of the SSER is to calculate public old age insurance. It covers the full population and provides full earnings information for employed and selfemployed in Switzerland since 1982. Earning records are not top-coded. This feature allow us to capture the true labor income distribution.

The SSER covers about $90 \%$ of the working age population (18 to 65 ). For more than 90\% of children born between 1967 and 1984, we have at least one non-negative income record between the age of 30 and 33 .

\section{Census}

Data on demographic characteristics, family ties and citizenship come from the population census, which is a collection of several register. To establish a link between parent and 
child, we use the INFOSTAR register. This register contains around $85 \%$ of all parent child relationships of the Swiss population. Linkages between parents and children can be missing, if parents never had any change in the civil register since 1990 - then the system never updated the social security records.

The main limitation is that family ties for migrants are not recorded if their birth took place before moving to Switzerland. ${ }^{4}$ We will take this into account by excluding nonSwiss people born in a foreign country. Excluding immigrants might be seen as a limitation. In terms of comparability we are in line with others studies, which also exclude immigrants from the sample (Chetty et al., 2014a). One could also argue that intergenerational mobility, which is also a measure for opportunities during childhood, should focus only on children that spent their whole childhood in a country.

\section{Survey Data}

In the last step, we link the structural survey with the SSER data. This data set is available since 2010 and surveys roughly 200,000 persons per year ( $2 \%$ of the population). As we have nine years available, we have a sample size of more than 1,600,000 unique observations (some individuals are surveyed multiple times). Variables that are included are, for example, information on education, religion, and occupation. Although this data is only available since 2010, this is not a drawback for us. Most variables we use, such as educational attainment or religion, can be assumed to stay constant after the age of 30 .

\subsection{Core Sample Definition}

The core sample consists of the child cohorts 1967 to 1984. To build this sample, we match the 2012 population census, the SSER and in the last step, the structural survey. As the census and the SSER cover the full population, virtually everybody has at least

\footnotetext{
${ }^{4}$ In case a family of migrants moved to Switzerland, their family ties are not recorded. In case the family has another child after moving to Switzerland, then the link between this particular child an its parents is recorded. However, it will appear as only child, as the link between siblings is not recorded.
} 
one record. Non-matched individuals are either dead or have emigrated. Since we observe income from the year 1982 until 2017, we restrict our sample to cohorts who are at least 15 years old in 1982 and at least 33 years old in 2017.

The core sample consists of (i) individuals born between 1967 and 1984, (ii) for whom we can identify mother and father, (iii) whose mean income is non-negative between the age of 30 and 33, (iv) and whose mean parent income is non-negative ${ }^{5}$ between child age 15 to 20. Conditional on being born in Switzerland, we have been able to link $72 \%$ of children to their father (with non-missing income). This share varies between $88 \%$ for the 1984 cohort and $56 \%$ for the 1967 cohort. ${ }^{6}$ Thus, we exclude children whose father or mother died or emigrated.

Even though our coverage of parent-child relationship is very large, we still want to check whether it is representative for Switzerland. Table A1 shows sample differences between the full population (1967 to 1984 cohorts) and the core sample. Since we exclude children whose mother or father is dead in 2012, our sample is slightly younger than the full population. Moreover, less parents are matched for foreigners and immigrants. Given that the differences are small or explainable, we conclude that our sample is representative for the full population of children born in Switzerland.

For the analysis on education in section 8, we merge the structural survey with our core sample. The survey is a random sample and does not cover the whole population. However, we still have roughly one third of the observations of our core sample $(n=$ 290, 061).

\subsection{Variables Definition and Descriptive Statistics}

Here, we describe our baseline specification of child and parent income. We also provide a summary statistic.

\footnotetext{
${ }^{5}$ Negative income are recorded when the income has to be corrected, the correction is recorded with a minus, and the amount has to be subtracted. Less than $0.0314 \%$ of observations have either negative mean father income or negative mean income

${ }^{6}$ More details on every cohort in Table A2.
} 


\section{Child Income}

We define income as the sum of wage earnings (employment and self-employment income), unemployment, and disability benefits. We deflate all incomes with the consumer price index (Swiss CPI). In the baseline specification, we measured children's income in their early thirties. The principal reason for this choice is to compare our estimates to the US. To smooth out transitory income shocks, we average income across four years. Thus, mean child income is the average child income during child age 30 to 33. For over $97 \%$ of the children, we observe at least one income between the age of 30 and 33 . For the remaining part, we set income equal zero. Finally, we excluded children if the average income between the age 30 to 33 is negative. In Section 9, we test the robustness of our baseline estimates using alternative age definitions. In Table 8 we asses the sensitivity to alternative samples income definitions.

\section{Parent Income}

Parent income is defined in the same way as child income. In the baseline specification, this is the average of a father's income when the child is between the 15 and 20 years. We also use family income to check for robustness. ${ }^{7}$ This is because of three reasons. First, we aim to capture the opportunities of a child while it is growing. The age between 15 to 20 is a decisive age in Switzerland because children decide which educational track they will follow. Thus, family income has supposedly a big effect. Second, parents are in mid-fourties when the child is 15 . This makes their rank in the income distribution stable and the life-time income bias negligible. The third reason for this choice is again comparability to the US. In Table 8, we assess the sensitivity of this choice, by varying child age at which father income is measured.

\footnotetext{
${ }^{7}$ We also use family income as the sum of mother and father income. Robustness checks show that our mobility estimates are not sensitive to family or father income. We use father income instead of family income in our main specification because of simplicity. Using mother income results in almost no intergenerational correlation. This is likely due to the low labor force participation of women in Switzerland for the mother cohorts of interest.
} 


\section{Summary Statistics}

Figure A1 shows the mean income by rank for father (left) and child (right). Inequality among children is lower than among fathers. Please note that the y-axes have different scales. The inequality difference occurs because of the later measurement of income among fathers. Mean age of fathers is around 45 and mean age of children is 33 .

Table 1 provides summary statistics for the core sample. Among children born between 1967 and 1984, 65\% are matched to both parents. Parents' characteristics are measured when the child is between the age of 15 and 20. Not surprisingly, fathers are on average older than mothers and have higher incomes. $75 \%$ of mothers still live in the same municipality as they used to live in 1995. Only a low share of mothers had a child during adolescence. Importantly, for virtually every father in our sample, we observe at least one income record between child age 15 and 20.

\section{$5 \quad$ National Estimates and Country Comparison}

In this section, we present our results. We show the estimates on relative mobility, absolute mobility, and compare Switzerland's estimates to other countries.

\subsection{Relative Mobility}

Table 2 shows the non-parametric transition matrix. It describes in which quintile children end up conditional on the parent quintile. For example, the estimate in parent quintile 1 (column 1) and child quintile 5 (row 5) indicates, that $12.9 \%$ of children from the bottom quintile end up in the top quintile. This statistic is also called «American Dream» measure (Q1Q5). As the table is rather cumbersome to compare to other countries, we move to more concise estimates of intergenerational income mobility.

Figure 1 plots the relationship between child and father rank. The blue points indicate the mean rank conditional on father rank. The red line is the prediction of a linear re- 
Table 1: Summary Statistics of Core Sample

\begin{tabular}{|c|c|c|}
\hline & Mean & St.Dev \\
\hline & (1) & (2) \\
\hline $\begin{array}{l}\text { Identified parents } \\
\text { Both parents }(\%) \\
\text { Mother }(\%) \\
\text { Father }(\%)\end{array}$ & $\begin{array}{l}65.22 \\
82.08 \\
70.85\end{array}$ & \\
\hline $\begin{array}{l}\text { Father Characteristics: Child 15-20 } \\
\text { Father Age } \\
\text { Father Age at Childbirth } \\
\text { Teenage birth }(\%) \\
\text { Swiss Father }(\%) \\
\text { Foreign Father }(\%) \\
\text { Father Non-Missing Income } \\
\text { Mean Income } \\
\text { Top } 20 \text { Income } \% \\
\text { Bottom } 20 \text { Income } \%\end{array}$ & $\begin{array}{c}47.67 \\
30.08 \\
0.43 \\
96.01 \\
3.99 \\
99.35 \\
100,576 \\
203,542 \\
93,726\end{array}$ & $\begin{array}{c}5.08 \\
5.09 \\
6.51 \\
19.58 \\
19.58 \\
8.04 \\
117,725 \\
229,897 \\
169,830\end{array}$ \\
\hline $\begin{array}{l}\text { Mother Characteristics: Child 15-20 } \\
\text { Mother Age } \\
\text { Mother Age at Childbirth } \\
\text { Teenage birth (\%) } \\
\text { Same municipality as in } 1995(\%) \\
\text { Swiss Mother (\%) } \\
\text { Foreign Mother (\%) } \\
\text { Mother Non-Missing Income } \\
\text { Mean Income } \\
\text { Top } 20 \% \\
\text { Bottom } 20 \%\end{array}$ & $\begin{array}{c}44.93 \\
27.36 \\
2.56 \\
74.84 \\
98.52 \\
1.48 \\
78.08 \\
23,572 \\
68,692 \\
0\end{array}$ & $\begin{array}{c}4.60 \\
4.61 \\
15.80 \\
43.40 \\
12.06 \\
12.06 \\
41.37 \\
37,664 \\
61,557 \\
0\end{array}$ \\
\hline $\begin{array}{l}\text { Parents: Child 15-20 } \\
\text { Married (\%) } \\
\text { Divorced (\%) } \\
\text { Mean Income } \\
\text { Top } 20 \% \\
\text { Bottom } 20 \%\end{array}$ & $\begin{array}{c}78.25 \\
11.39 \\
62,074 \\
118,819 \\
25,714\end{array}$ & $\begin{array}{c}41 \\
32 \\
62,979 \\
121,202 \\
9,130\end{array}$ \\
\hline Obs. & 849,543 & \\
\hline
\end{tabular}

Notes: This table describes the sample which we use for our national and regional estimates. All amounts are expressed in 2017 Swiss Francs. 
Table 2: National Quintile Transition Matrix

\begin{tabular}{lccccc}
\hline & \multicolumn{5}{c}{ Parent quintile } \\
Child quintile & 1 & 2 & 3 & 4 & 5 \\
\hline 1 & 24.6 & 21.7 & 19.6 & 18.0 & 16.2 \\
2 & 23.0 & 21.0 & 19.5 & 18.5 & 18.1 \\
3 & 21.6 & 22.4 & 20.8 & 18.6 & 16.5 \\
4 & 18.0 & 20.3 & 21.7 & 21.3 & 18.7 \\
5 & 12.9 & 14.6 & 18.4 & 23.6 & 30.5 \\
\hline \hline
\end{tabular}

Notes: This table shows in which quintile children end up in the income distribution for every quintile of the parent's income distribution. Each cell describes in which quintile (row) children end up conditional on the parent quintile (column). Parent quintile is based on father income. For example, $16.3 \%$ of children from parent's in the top quintile of the income distribution will end up in the bottom quintile of the income distribution. $12.9 \%$ of children from parent's of the bottom quintile of the income distribution end up in the top quintile («American Dream measure»).

Income ranks are measured relative to child cohort. The table includes children born in Switzerland from 1967 to 1984 and consists of 849,849 observations (child-father pairs).

gression of child rank on father rank. The functional form of the relationship is strikingly linear. As described earlier, this linearity seems to be an empirical phenomenon that has been observed in other countries. It justifies the use of a linear regression to summarize the rank-rank relationship. Figure A2 in the appendix shows the same graph for family income rank (Panel A). The difference between family and father rank is very small. Table A3 reports the results for alternative sub-samples. There is practically no correlation between mother and child rank.

The slope of the rank-rank relationship is 0.153 (RRS). This is the same as saying that the difference in child rank outcome between the highest and the lowest father rank is 15.3 ranks. Ranks can also be expressed in monetary units. A child with a father in the lowest rank can expect to earn roughly 56,000 Swiss Francs ( $\approx 56,000$ USD), while a child from the father in the highest percentile rank can expect to earn 68,000 Swiss Francs. ${ }^{8}$ The difference of around 12,000 Swiss Francs corresponds to roughly twice the median monthly salary in Switzerland.

The constant in the regression in Figure 1 is 41.9. This is the rank a child with a father

\footnotetext{
${ }^{8}$ Mean income for each rank can be found in Table A4 in the appendix.
} 


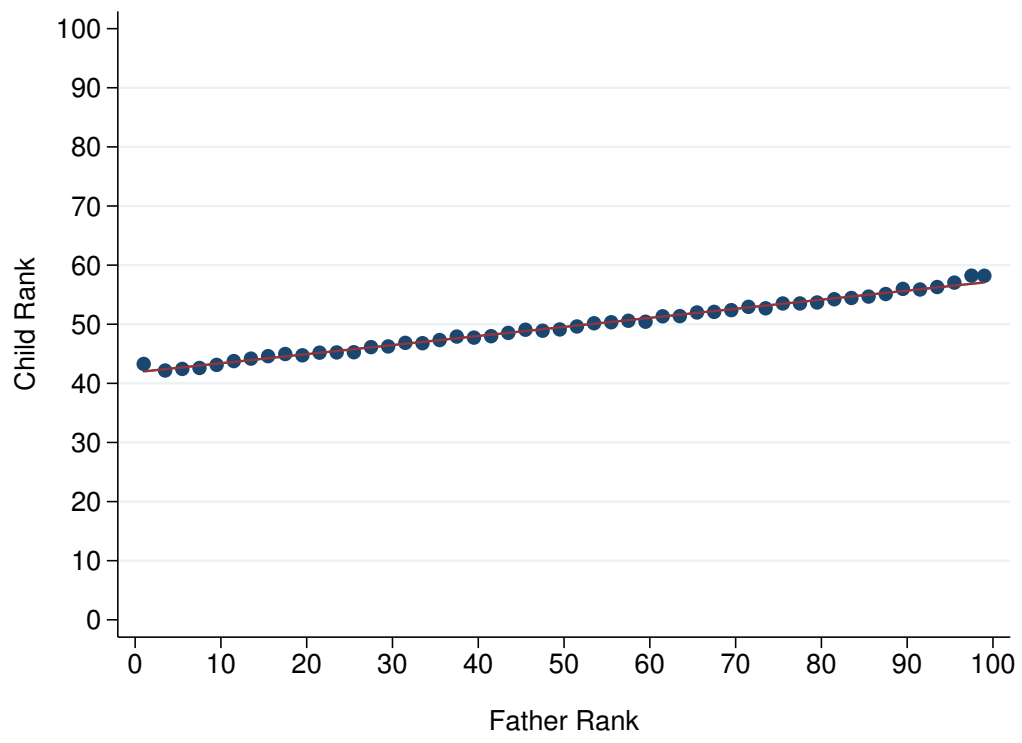

Figure 1: Relative Income Mobility: Father and Child Rank

Notes: This figure shows the expected rank of children conditional on father's rank. The blue dots depict the mean rank of children for two father ranks. The red line is the prediction of OLS regression of child rank on father rank, based on the whole sample consisting of 849,849 observations (child-father pairs). The OLS regression yields a constant of 41.9 and a slope of 0.153 . The $R^{2}$ is 0.02 . The estimated rank-rank slope of 0.153 is a measure for relative mobility. The higher this slope, the more child income depends on father income, hence the lower income mobility. The rank difference of children from the poorest and the richest parents equals the slope $\times 100$, and is 15.3 in our case. This is sometimes also called the «wedge» between children from the highest and lowest parent's percentile. 
from the lowest rank can expect. Furthermore, the $R^{2}$ of the regression is only 0.02 . While there is clearly a positive relationship between father and child rank, father's rank is only a weak predictor of the child income rank. The low $R^{2}$ is not idiosyncratic to Switzerland, but has been documented in other countries as well, for example in Italy Acciari et al. (2019).

For sake of completeness, we also calculate the intergenerational elasticity estimate (IGE) in Table A3. Regressing logarithmized child income on logarithmized father income yields an elasticity of 0.141 . This means that a $10 \%$ increase in father's income is associated with a $1.41 \%$ increase in child income. However, as explained in section 5, the IGE has several shortcomings and should be interpreted with caution. The baseline specification excludes incomes equal to zero. In Table A3, we report the results for alternative specifications and find that the IGE is sensitive to changes in specifications.

\subsection{Absolute Mobility}

Next, we move to absolute mobility. Table 3 shows the share of children earning more than their parents. At the age of $40,38.7 \%$ of children earn more than their father did at the same age. $80.9 \%$ of children earn more than their mother at that age. There is a strong discrepancy between gender. More than half of the sons earn more than their father did, while merely $18 \%$ of the daughters earn more than their father. Comparing daugthers to their mothers shows that more than $70 \%$ earn more than their mothers.

Figure 1 also implicitly informs on absolute mobility. We are interested in the expected child rank conditional on having a father from rank 25. A child with a father below the median can expect to achieve rank 46. Because the relationship is linear, this is the same as asking what rank a child with a father from rank 25 can expect. Thus, a child from a father at rank 25 can expect to achieve a higher rank herself, but still a rank below the median. 
Table 3: Share of Children with higher Real Income than their Parents

\begin{tabular}{lccc}
\hline \hline Child Sample & Age & Share $>$ Father & Share $>$ Mother \\
\hline All Genders & 35 & 38.1 & 83.6 \\
All Genders & 40 & 38.7 & 80.9 \\
Daughters & 35 & 20.5 & 76.8 \\
Daughters & 40 & 18.2 & 71.8 \\
Sons & 35 & 52.6 & 89.2 \\
Sons & 40 & 54.3 & 87.9 \\
\hline \hline
\end{tabular}

Notes: Share in percentages of children earning more in real terms than their mother or father at the same age of 35 or 40 . For example, $38.1 \%$ of all children earn more at age 35 than their father did at the age of 35 . Looking only at sons, row 5 shows that $52.6 \%$ of sons earn more than their father at age 35. On contrast, only $20.5 \%$ of daughters earn more than their father at age 35 , but $76.8 \%$ of daughters earn more than their mother at the age of 35 . Income is deflated with the consumer price index (CPI). Income also includes income from social insurances.

\subsection{Cross-Country Comparison}

How can these national estimates be interpreted? Table 4 puts the mobility estimates of Switzerland in context to other countries. Switzerland has the highest mobility estimates in almost all statistical measures. Cross-country comparison depends on the exact specification of the underlying data. To enhance comparability, we have only chosen studies that use administrative data and have been published in the last 10 years.

In virtually all measures, Switzerland has the highest mobility estimates. One exception is the «American Dream (Q1Q5)» measure: In Sweden children from the bottom quintile are more likely to reach the top quintile than in Switzerland. 
Table 4: Mobility Estimates Country Comparison

\begin{tabular}{lcccc}
\hline \hline & Switzerland & United States & Sweden & Italy \\
\hline Measure & (Chuard \& Grassi, 2020) & (Chetty et al., 2014a) & (Heidrich, 2017) & (Acciari et al., 2019) \\
\hline RRS & 0.15 & 0.34 & 0.18 & 0.25 \\
IGE & 0.14 & 0.45 & 0.29 & 0.25 \\
Q1Q5 (in \%) & 12.9 & 7.5 & 15.7 & 10 \\
AUM25 & 46 & 41.4 & 43.6 & 44 \\
\hline Income & Lab & Lab\&Cap & Lab & Lab\&Cap \\
Data & SocSec & Tax & SocSec & Tax \\
\hline \hline
\end{tabular}

Notes: This table compares results of recent studies on intergenerational income mobility that use high quality data and are thus likely to provide reliable results. $R R S$ stands for rank-rank slope. The higher the RRS, the lower relative income mobility. IGE stands for intergenerational elasticity. The higher the IGE, the lower relative income mobility. Q1Q5 is the «American Dream» measures. It reports the share of children from the bottom quintile that make it to the top quintile. The higher this measure, the more likely the «American Dream». A plausible upward limit of this measure is 20\%. AUM25 stands for absolute upward mobility at percentile 25 . It shows where children with parents at the 25 th percentile of the income distribution can expect to end up. This follows from the prediction of the rank-rank slope regression. It also shows where children with parents below the median can expect to end up.

Income describes which kind of income is used to for the measurements. Lab stands for Labor income, Cap stands for Capital income. Data describes the data source. SocSec stands for Social Security register, Tax stands for tax data.

\section{Education and Parental Income}

Switzerland is well known for its vocational education system. More than $70 \%$ of the students earn a vocational degree after compulsory school. Less than $20 \%$ visit a gymnasium (high school). At the end of the gymnasium, students receive a «matura» degree, which is an entry ticket to almost all studies at the university level. ${ }^{9}$ Thus, the natural question arises, if this peculiar education system could be a reason for the high mobility estimates.

To investigate this question, we are first interested in educational mobility: The relationship between child education and father's income. Figure 2 shows the share of students with a vocational and a gymnasium degree. This «fishlike» picture in Panel (a) is quite striking. Despite our high income mobility estimates, educational mobility is low. Below father's rank 50 , merely $12 \%$ of the children visit a gymnasium. Above rank 50 , the ratio

\footnotetext{
${ }^{9}$ One notable exception are medical studies. Here, applicants are required to take an entry exam.
} 


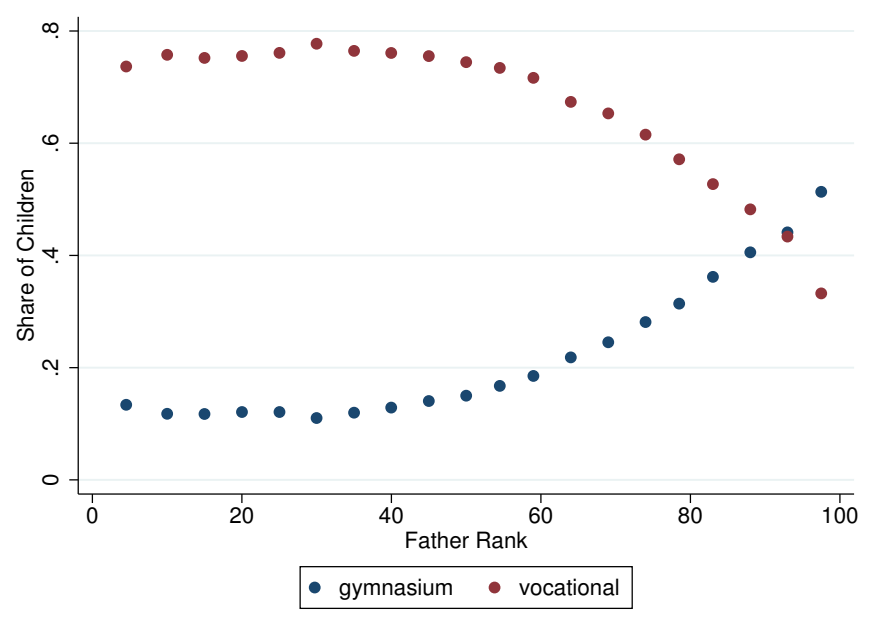

(a) Vocational vs. Gymnasium

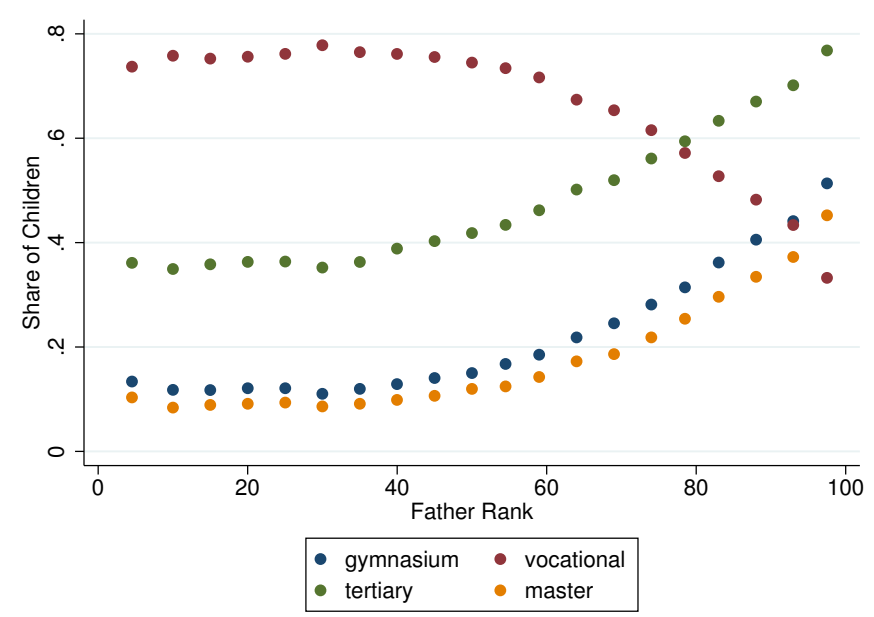

(b) Several Education Choices

Figure 2: Educational Mobility

Notes: This figures shows how education and father's rank in the income distribution are related. Panel (a) plots the share of children going to vocational training and those going to gymnasium after compulsory school. The educational track highly depends on father's income. Panel (b) adds the share of children with master's degree from a university and «any» tertiary education, which can be obtained from any institute of higher education - not only university. The sample is based on 290,061 observations and covers the child cohorts 1967 to 1984. 
is strictly increasing. As of father rank 95, more children opt for gymnasium than for vocational training. This finding of low educational mobility is consistent with earlier evidence provided by Bauer and Riphahn (2007). They show that educational outcome of parents and children are highly correlated. ${ }^{10}$

Panel (b) in Figure 2 adds a further layer to the educational mobility picture: The share of children with a tertiary degree and a master's degree. Tertiary degrees can be obtained from university, a university of applied sciences or from other higher vocational education institutes. Thus, gymnasium is not a prerequisite for a tertiary degree. In contrast, master's degree are almost exclusively obtained via university. Thus, for a master's degree gymnasium is a prerequisite in most cases. ${ }^{11}$

Panel (b) in Figure 2 shows that the share of children obtaining a master's degree is highly correlated with the share of students going to gymnasium and increases strictly with father income. However, looking at «any» tertiary degree, there are relatively more students with fathers of lower ranks. This means, even without gymnasium, many students end up with some sort of tertiary education. To sum up, educational mobility is low for university-based education. It is, however, much higher if all sorts of education are taken into account. Those results confirm the often hailed high permeability of the Swiss education system: Even without a formal academic education that starts in gymnasium, many children achieve high educational outcomes. This in turn is likely to increase income across all parent ranks and thus likely to increase upward mobility.

In the previous paragraphs, we were looking at educational mobility. Now we are interested in how upward mobility depends on the educational path. Which education increases the likelihood of moving from the bottom to the top quintile? When looking at upward mobility, we restrict our sample to children with a father income in the lowest

\footnotetext{
${ }^{10}$ Precisely, Bauer and Riphahn (2007) find that children with at least one parent with university education have a probability of $62 \%$ to obtain a university degree, whereas children of parents without academic background have a probability of $25 \%$ to move up the educational ladder.

${ }^{11}$ Some universities of applied sciences, for which gymnasium is not a prerequisite, offer master's degree courses. However, those are very few and they only increased slightly in recent years, which is unlikely to be relevant for our studied cohorts.
} 
Table 5: Logit Regression Education and Upward Mobility

\begin{tabular}{|c|c|c|c|c|c|c|c|c|}
\hline & \multicolumn{4}{|c|}{ «American Dream» } & \multicolumn{4}{|c|}{ «Medium Upward Mobility» } \\
\hline & \multicolumn{4}{|c|}{$R_{c}>80 \mid R_{f}<20$} & \multicolumn{4}{|c|}{$R_{c}>50 \mid R_{f}<20$} \\
\hline & (1) & $(2)$ & (3) & $(4)$ & $(5)$ & $(6)$ & $(7)$ & (8) \\
\hline Gymnasium & $\begin{array}{l}0.833^{* * *} \\
(0.0365)\end{array}$ & $\begin{array}{l}1.048^{* * *} \\
(0.0405)\end{array}$ & & & $\begin{array}{l}-0.0260 \\
(0.0346)\end{array}$ & $\begin{array}{l}0.237^{\text {*** }} \\
(0.0381)\end{array}$ & & \\
\hline University Master & & & $\begin{array}{l}2.229^{* * *} \\
(0.0415)\end{array}$ & $\begin{array}{l}2.255^{* * *} \\
(0.0451)\end{array}$ & & & $\begin{array}{l}0.424^{* * *} \\
(0.0396)\end{array}$ & $\begin{array}{c}0.546^{* * *} \\
(0.0437)\end{array}$ \\
\hline Other Tertiary & & & $\begin{array}{l}1.651^{* * *} \\
(0.0358)\end{array}$ & $\begin{array}{l}1.584^{* * *} \\
(0.0377)\end{array}$ & & & $\begin{array}{l}0.767^{* * *} \\
(0.0259)\end{array}$ & $\begin{array}{c}0.771^{\text {*** }} \\
(0.0283)\end{array}$ \\
\hline Female & & $\begin{array}{c}-1.338^{* * *} \\
(0.0353)\end{array}$ & & $\begin{array}{c}-1.224^{* * *} \\
(0.0356)\end{array}$ & & $\begin{array}{c}-1.360^{* * *} \\
(0.0244)\end{array}$ & & $\begin{array}{r}-1.345^{* * *} \\
(0.0244)\end{array}$ \\
\hline Cantons FE & No & Yes & No & Yes & No & Yes & No & Yes \\
\hline Observations & 39,875 & 39,875 & 39,875 & 39,875 & 36162 & 36,162 & 36,162 & 36,162 \\
\hline
\end{tabular}

Standard errors in parentheses

${ }^{*} p<0.05,{ }^{* *} p<0.01,{ }^{* * *} p<0.001$

Notes: Standard errors in parentheses: ${ }^{*} p<0.05,{ }^{* *} p<0.01,{ }^{* * *} p<0.001$

Dependent variable $R_{c}>80$ (Columns 1 to 4 ) is 1 if a child with a father from the bottom quintile achieves rank 80 or higher and 0 if they stay below rank 80 .

Dependent variable $R_{c}>50$ (Columns 5 to 8) is 1 if a child with a father from the bottom quintile achieves rank 50 or higher, and zero if they stay below rank 50. Children making it to rank 80 or higher are dropped as they are captured in columns 1 to 4 . 
quintile.

In Table 5 we use a logit model to analyze how upward mobility depends on education. In columns (1) to (4) the outcome variable indicates if someone from the bottom quintile makes it to the top quintile - the «American Dream» measure. Columns (5) to (8) show «medium upward mobility». This measure is less ambitious and equals one if a child makes it above rank 50. Here, we also drop observations if they make it higher than 80 , as this is captured in the American Dream measure.

Columns (1) and (2) show that likelihood to achieve the «American Dream» is higher if a child went to gymnasium. In contrast, columns (5) and (6) show that going to gymnasium is less strongly associated with «medium upward mobility». Comparing columns (3) and (4) to columns (7) and (8), shows that having a university master increases the likelihood of making it to the top quintile much more than making it above the median. Thus for «medium upward mobility», the vocational education system (vocational education and any tertiary degree) is beneficial. At the same time, the results suggest that academic education (gymnasium and university) is key to make it to the top.

Those findings could have important consequences. They suggest that the vocational education system is beneficial for medium upward mobility and therefore results in good rank-rank slopes estimates for Switzerland. But to really make it to the top, academic education is still important. And because academic educational mobility is low, the strong vocational system - that is likely to increase medium upward mobility - comes at the costs of loosing some «Einsteins». Those are talents that come from the bottom of the income distribution, but did not have the chance to make it to the top (Bell et al., 2019). In line with this hypothesis is our result that the «American Dream» is less likely achieved in Switzerland compared to Sweden, while the overall relative mobility is higher in Switzerland (see Table 4).

Looking more closely at the different professions learned during vocational training, Table 6 shows that upward mobility differs between vocations. It lists the 21 most frequently learned professions. Together they account for $53 \%$ of all professions. A negative sign in 
column (3) indicates, that there are more «climbers» than «stayers» in that profession. It turns out, that professions associated with moving up are either related to STEM professions (science, technology, engineering, mathematics), such as «electricians», «electronics and mechanics and services» or «information and communications» or related to banks, e.g. «bank teller». Thus, the likelihood to climb up is higher for children with a STEM and banking vocational training.

Table 6: Learned Professions and Upward Mobility

\begin{tabular}{lcccc}
\hline \hline & $\begin{array}{c}(1) \\
\text { Rank }>80 \\
\text { «Climber» }\end{array}$ & $\begin{array}{c}(2) \\
\text { Rank }<80 \\
\text { «Stayers» }\end{array}$ & $\begin{array}{c}(3) \\
\text { Diff } \\
\text { Difference }\end{array}$ & $\begin{array}{c}(4) \\
\text { Full Voc Sample }\end{array}$ \\
\hline General office clerks & 0.102 & 0.137 & $0.009^{* * *}$ & 0.152 \\
Shop sales assistants & 0.012 & 0.087 & $0.019^{* * *}$ & 0.064 \\
Nursing professionals & 0.007 & 0.029 & $0.008^{* * *}$ & 0.030 \\
Carpenters and joiners & 0.014 & 0.040 & $0.006^{* * *}$ & 0.027 \\
Electricians & 0.031 & 0.022 & $-0.002^{* *}$ & 0.025 \\
Motor vehicle mechanics & 0.018 & 0.032 & $0.003^{* * *}$ & 0.024 \\
Draughtspersons & 0.015 & 0.020 & $0.001^{*}$ & 0.024 \\
Metal, machinery and related & 0.023 & 0.018 & -0.001 & 0.019 \\
Cooks & 0.007 & 0.026 & $0.005^{* * *}$ & 0.019 \\
Hairdressers & 0.002 & 0.023 & $0.005^{* * *}$ & 0.018 \\
Crop and animal producers & 0.026 & 0.052 & $0.008^{* * *}$ & 0.017 \\
Gardeners & 0.005 & 0.020 & $0.004^{* * *}$ & 0.014 \\
Bakers and confectionery & 0.004 & 0.021 & $0.004^{* * *}$ & 0.014 \\
Bank tellers & 0.024 & 0.008 & $-0.005^{* * *}$ & 0.013 \\
Plumbers and pipe fitters & 0.009 & 0.013 & $0.001^{* * *}$ & 0.013 \\
Medical assistants & 0.001 & 0.011 & $0.002^{* * *}$ & 0.013 \\
Pharmaceutical assistant & 0.002 & 0.013 & $0.003^{* * *}$ & 0.012 \\
Dental assistants & 0.002 & 0.011 & $0.002^{* * *}$ & 0.011 \\
Electronics mechanics and servicers & 0.014 & 0.007 & $-0.001^{* *}$ & 0.010 \\
Social work associate professionals & 0.002 & 0.008 & $0.003^{* * *}$ & 0.009 \\
Information and communications & 0.025 & 0.004 & $-0.006^{* * *}$ & 0.009 \\
\hline Observations & 3,319 & 25,569 & 131,135 & 138,743 \\
\hline \hline
\end{tabular}

Notes: The table shows a list with the 21 most learned professions (during vocational track). Together those professions account for $53 \%$ of all learned professions. Column 1 shows the ratio of «climbers» among the professions, while column 2 shows the ones that stay in the bottom quintile. 


\section{The Geography of Mobility}

We analyze mobility on two geographical units: canton and labor market region (MS). Cantons are political entities with large authority in policy setting. Labor market regions depict commuting patterns and are constructed by the Swiss Federal Office of Statistics, similar to commuting zones in the US. Our main focus lies on cantonal variation. This is because it allows to correlate the results with other variables, such as GDP per capita, or share of students at high school. This information is not available on commuting zone level. Furthermore, cantons differ strongly in many aspects, such as taxes and education, therefore mobility differences of cantons are of genuine interest.

In the main specification we use the mother's municipality in 2010 to approximate childhood location because we do not have panel information on the exact location until 2010. In the robustness section we show that the results of our maps are robust to several location specifications (see Section 9.3).

\subsection{Cantonal Differences}

Absolute mobility differs considerably between cantons. ${ }^{12}$ Figure 3 shows how intergenerational mobility varies across cantons. The precise point estimates and the 95\% confidence interval are shown in Figure 4. Panel (a) in Figure 4 shows absolute mobility at father's percentile rank 25 for each canton. The horizontal line indicates the national average and its 95\% confidence interval. Absolute mobility varies substantially across cantons: Eight cantons have significantly higher absolute mobility than the national average. At the same time, 10 cantons have significantly lower absolute mobility. Panel (a) in Figure 3 plots the estimates to a map.

Relative mobility is more homogeneous across cantons. Panel (b) in Figure 4 shows relative mobility in terms of rank-rank slope. ${ }^{13}$ In contrast to absolute mobility, fewer

\footnotetext{
${ }^{12}$ Figure A3 shows the rank-rank relationship for all cantons.

${ }^{13}$ More precisely, rank-rank slope multiplied by 100
} 
cantons differ significantly from the national estimate. In five cantons, relative mobility exceeds the national estimate. In merely two cantons, mobility falls below the national estimate.

Panel (b) in Figure 3 shows absolute mobility at father rank 25 ( $\approx 63,800 \mathrm{CHF}$ ) on a map. The expected rank of a child with a father from the bottom half of the income distribution varies between $50(\approx 62,000 \mathrm{CHF})$ in the canton $《 \mathrm{Zug} »$ and $43(\approx 56,000 \mathrm{CHF})$ in the canton of «Basel-Stadt». The difference between those incomes corresponds to roughly one monthly median salary in Switzerland and is similar to the regional difference in Sweden. ${ }^{14}$ The variation is much smaller than in the US, where absolute mobility at $p=25$ varies between $36(\approx \$ 26,300)$ in Charlotte and $46(\approx \$ 37,900)$ in Salt Lake City (Chetty et al., 2014a).

The «American Dream (Q1Q5)» measure is highly correlated with absolute mobility. Panel (c) of Figure 3 shows the share of people with a father from the bottom quintile that make it to the top quintile. Almost $20 \%$ from the canton «Geneva» and «Zurich» make it to the top. This share is considerably smaller in other areas of Switzerland.

\subsection{Commuting Zone Differences}

Figure 5 shows the same maps based on commuting zones (MS regions). Overall, the maps look quite similar to the ones based on cantons. Figure 6 depicts the estimates based and confidence intervals based on commuting zones. Absolute moblity estimates are more often significantly different from the national average than relative mobility estimates. In terms of point estimates, the absolute mobility estimates span over a larger interval than compared to the cantonal estimates. This is not surprising because there are 106 commuting zones compared to 26 cantons.

\footnotetext{
${ }^{14}$ Heidrich (2017) finds that absolute mobility at $p=25$ varies from 41 in Arjäng to 49 in Värnoma. In terms of income, this difference mounts to $90 \%$ of a monthly salary in Sweden.
} 


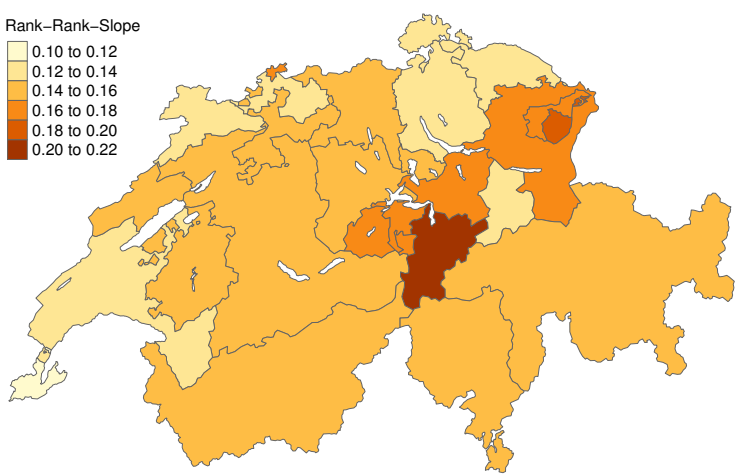

(a) Rank-Rank Slope

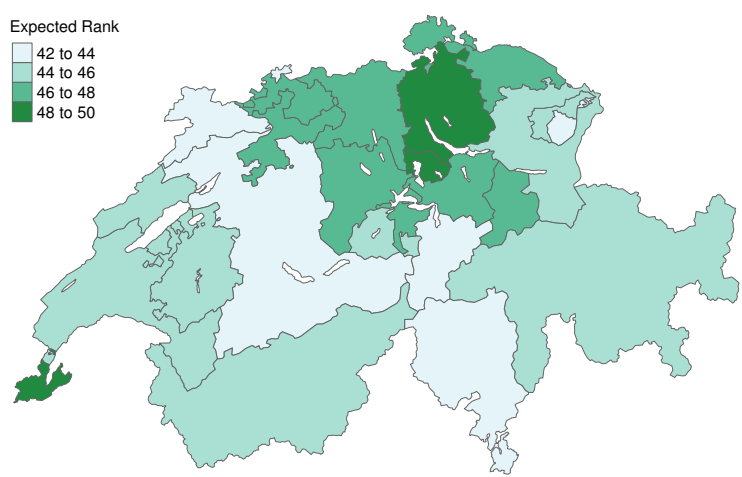

(b) Expected Rank of Children with Father at Rank 25

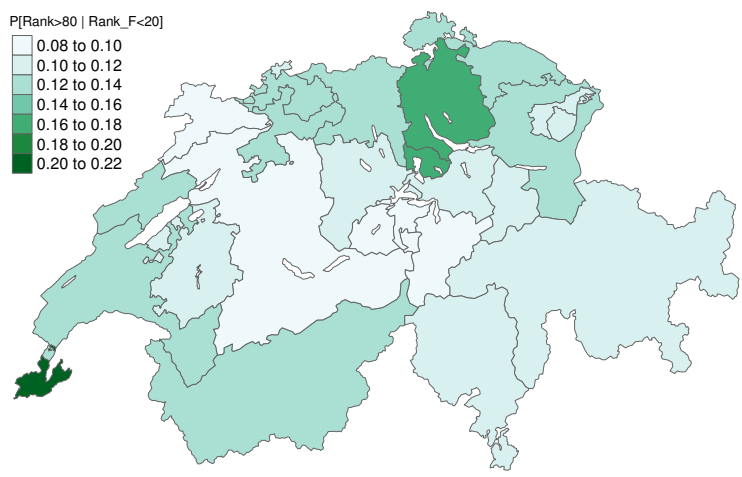

(c) Share of Children reaching «American Dream» (Reach Top 20 from Bottom 20)

Figure 3: Income Mobility Estimates by Canton

Notes: The three figures present heatmaps on intergenerational mobility across cantons. Children are assigned to the location, where their mother lived in the year 2010.

Panel (a) shows the resulting slope of the OLS regression of child rank on father rank. The higher the slope, the lower relative income mobility. Ranks are defined in the national income distribution.

Panel (b) shows where children from fathers at the rank 25 can expect to end up in the income distribution. This estimate follows from a prediction of the OLS rank-rank regressions by canton. Ranks are defined in the national income distribution. Rank 25 in father income corresponds to 63,800 Swiss Francs gross labor income (deflated to 2017). Ran 250 in the child income distribution corresponds to roughly 62,800 Swiss Francs, rank 43 in the child income distribution to roughly 56,800 Swiss Francs. Panel (c) shows the share of children from the bottom quintile of the (national) income distribution that make it to the top quintile of the (national) income distribution. 


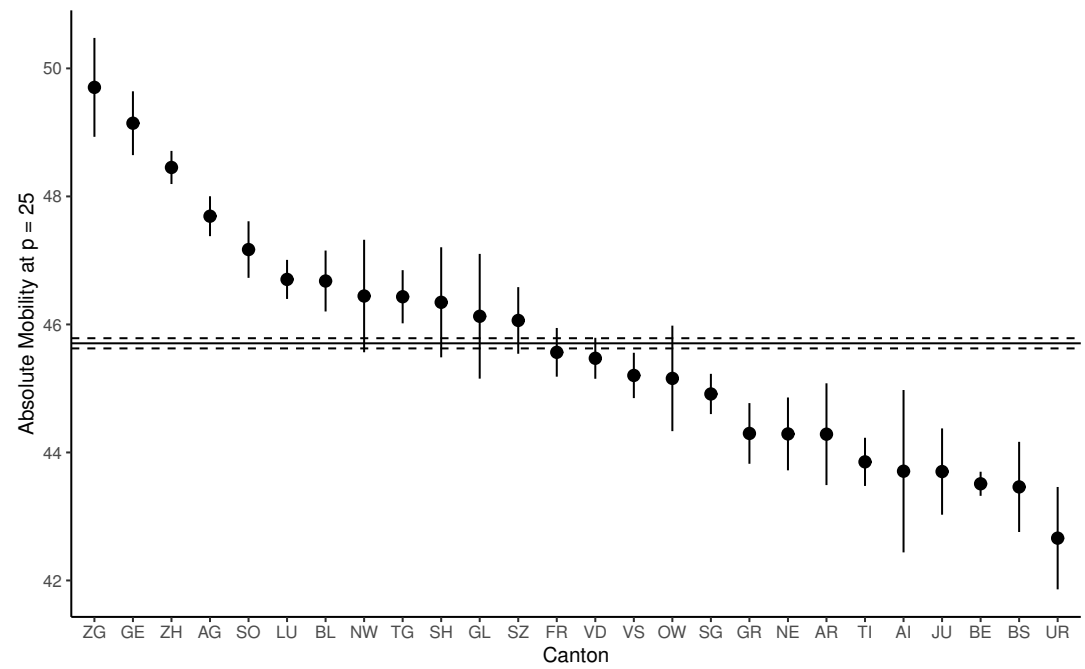

(a) Absolute Mobility at $\mathrm{p}=25$

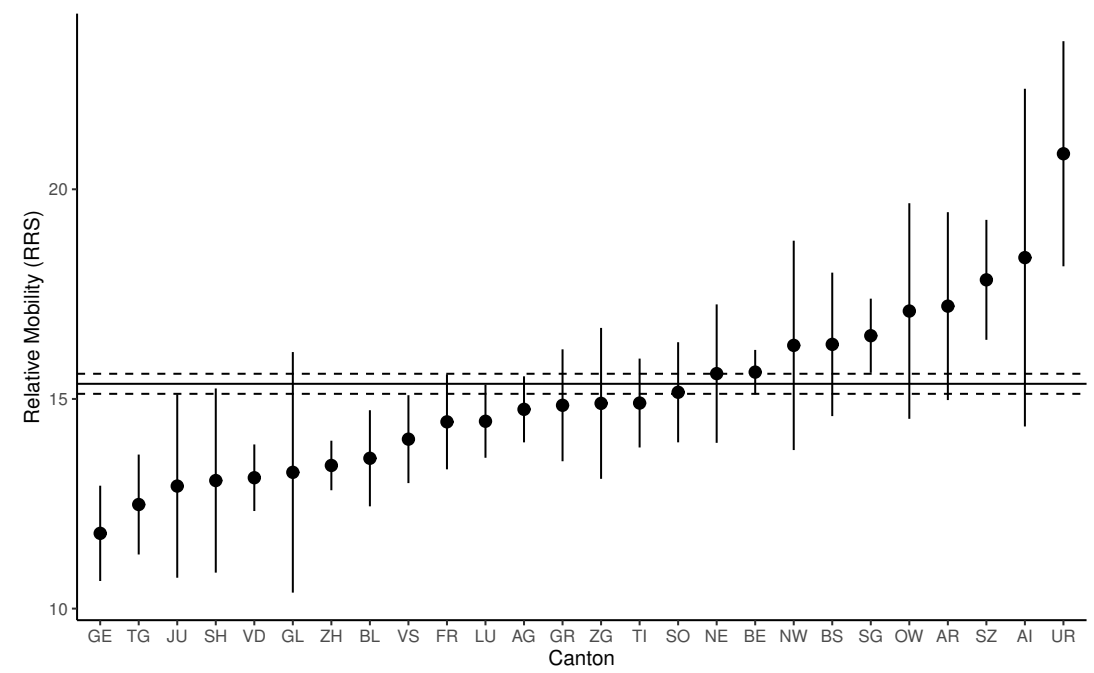

(b) Relative Mobility

Figure 4: Coefficient Plot Estimates Canton

Notes:

Panel (a) shows the rank that children with fathers at rank 25 of the income distribution can expect to achieve. This is referred to as absolute mobility. The points indicate the point estimate and the line indicates the $95 \%$ confidence intervals for each canton. These estimates follow from a prediction of the OLS rank-rank regressions by canton. Ranks are defined in the national income distribution. Cantons are ordered by the absolute mobility estimates. On the left are cantons with highest absolute mobility, on the right cantons with lowest absolute mobility. A higher point estimate means higher absolute mobility. The horizontal line depicts the national average and the $95 \%$ confidence interval of the national average. Panel (b) looks at relative mobility. The points indicate the estimated rank-rank slope which follows from a regression of child rank on father rank for each canton separately. Ranks are defined according to the national income distribution. The vertical line indicates the $95 \%$ confidence interval. Cantons are ordered by relative mobility estimates. On the left are cantons with highest relative mobility estimates, on the right cantons with lowest relative mobility estimates. A higher slope means lower relative mobility. The horizontal line depicts the national average and dashed horizontal line the $95 \%$ confidence interval of the national average. 


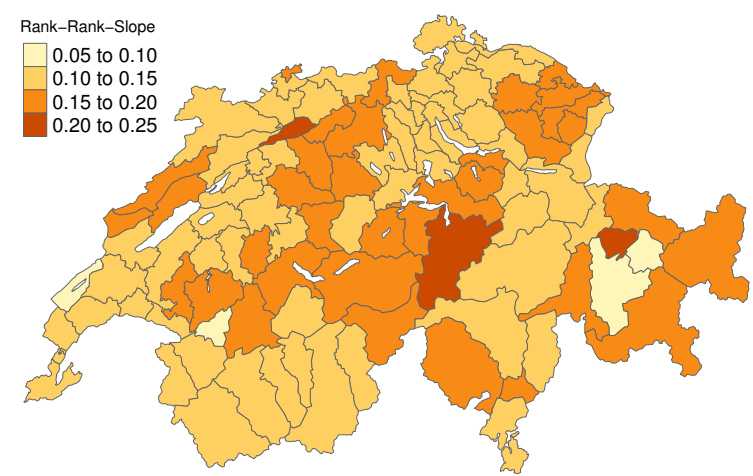

(a) Rank-Rank-Slope

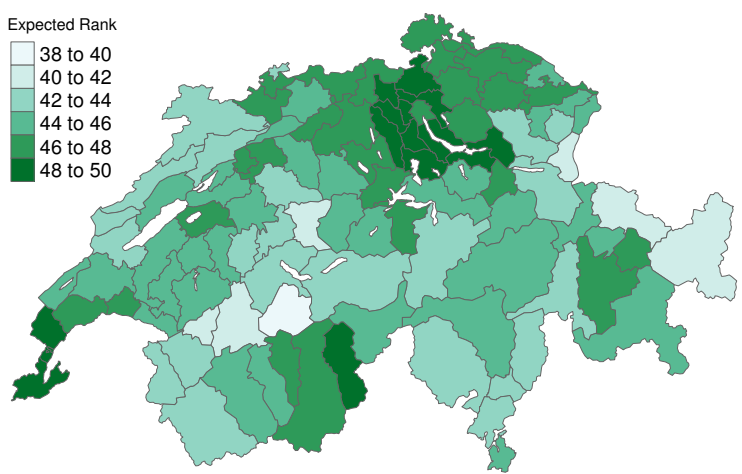

(b) Expected Rank of Child with Father at Rank 25

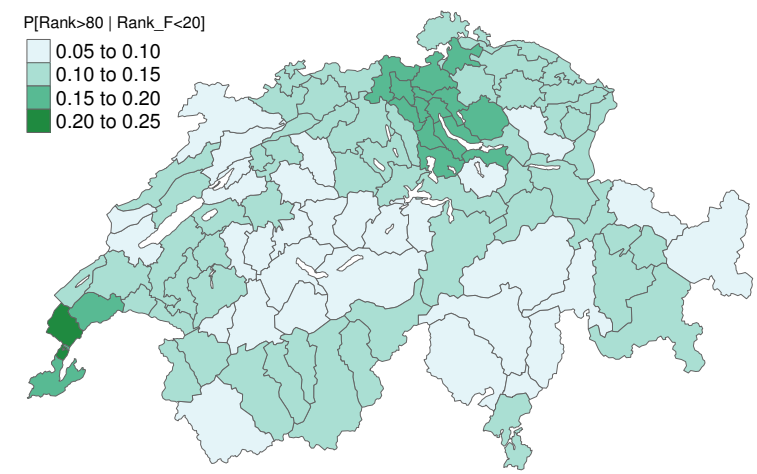

(c) Share of Children Reaching Top 20 from Bottom 20

Figure 5: Mobility Estimates by Commuting Zones (MS Regions)

Notes: The three figures present heatmaps on intergenerational mobility across commuting zones. Children are assigned to the location, where their mother lived in the year 2010.

Panel (a) shows the resulting slope of the OLS regression of child rank on father rank. The higher the slope, the lower relative income mobility. Ranks are defined in the national income distribution.

Panel (b) shows where children from fathers at the rank 25 can expect to end up in the income distribution. This estimate follows from a prediction of the OLS rank-rank regressions by commuting zone. Ranks are defined in the national income distribution. Rank 25 in father income corresponds to 63,800 Swiss Francs gross labor income (deflated to 2017). Rank 50 in the child income distribution corresponds to roughly 62,800 Swiss Francs, rank 43 in the chil\$4ncome distribution to roughly 56,800 Swiss Francs. Panel (c) shows the share of children from the bottom quintile of the (national) income distribution that make it to the top quintile of the (national) income distribution. 


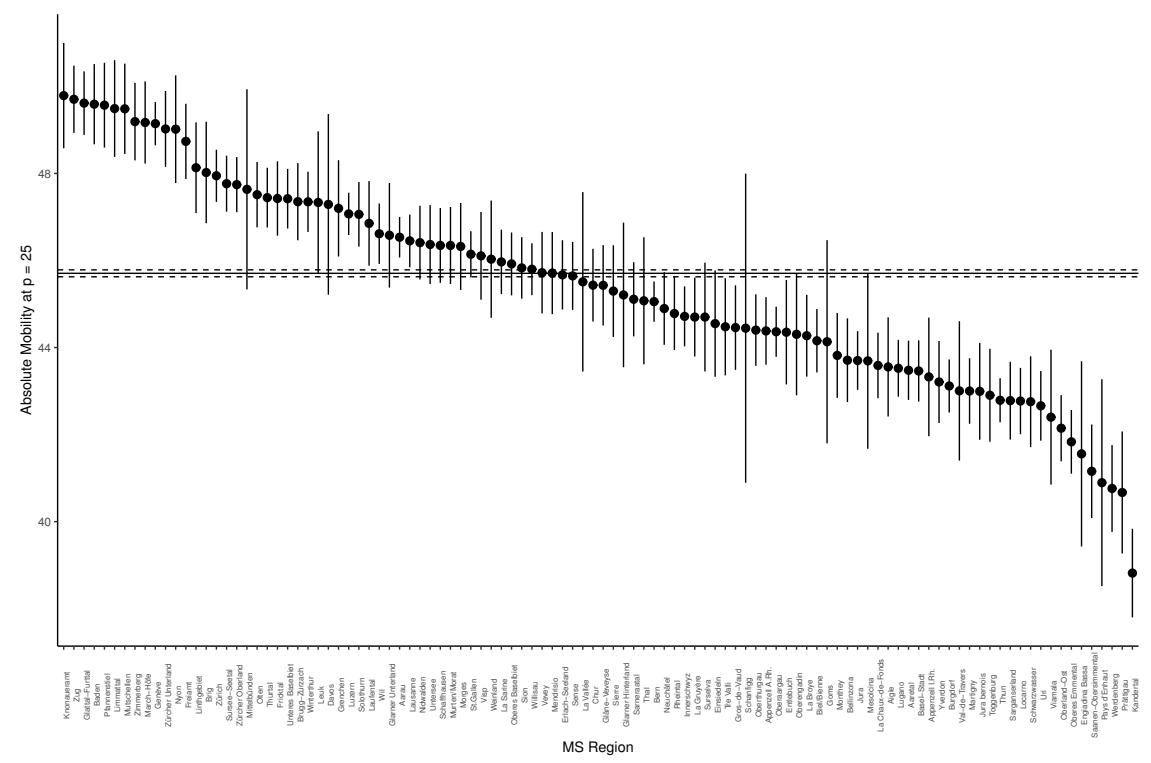

(a) Absolute Mobility (RRS)

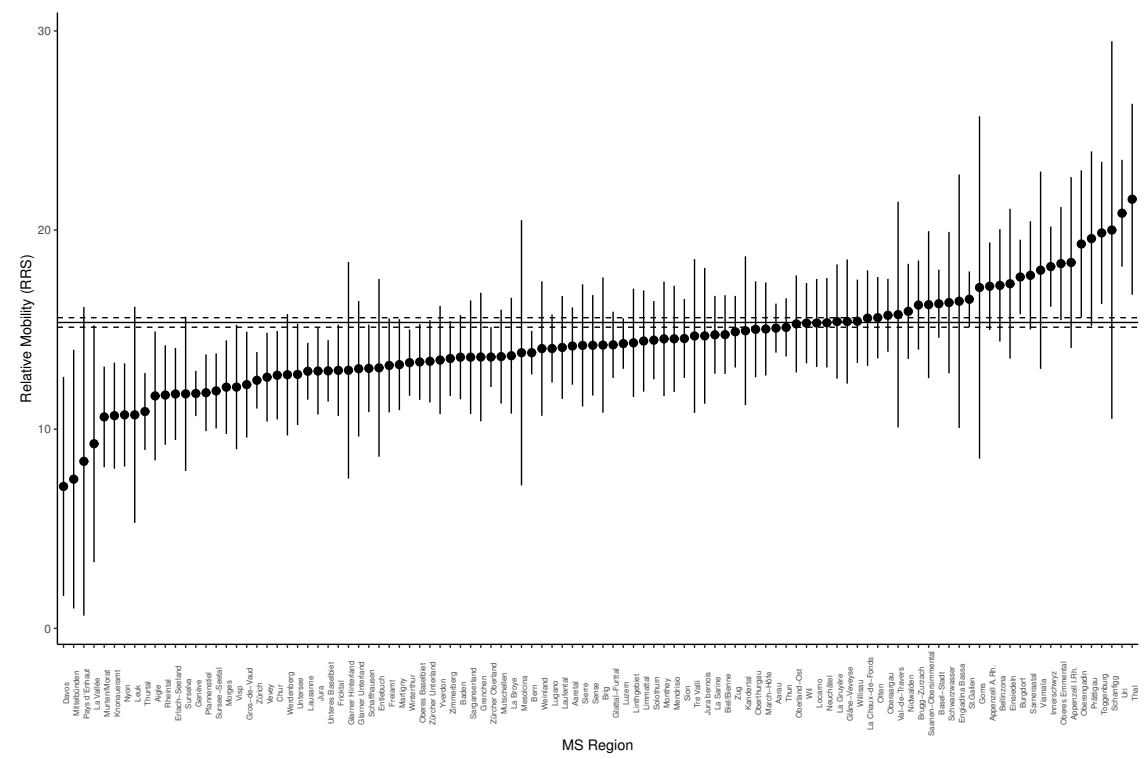

(b) Relative Mobility

Figure 6: Coefficient Plot Estimates by MS-Regions

Notes: Panel (a) shows the rank that children with fathers at rank 25 of the income distribution can expect to achieve. This is referred to as absolute mobility. The points indicate the point estimate and the line indicates the $95 \%$ confidence intervals for each commuting zone. These estimates follow from a prediction of the OLS rank-rank regressions by commuting zone. Ranks are defined in the national income distribution. Commuting zones are ordered by the absolute mobility estimates. On the left are commuting zones with highest absolute mobility, on the right commuting zones with lowest absolute mobility. A higher point estimate means higher absolute mobility. The horizontal line depicts the national average and the $95 \%$ confidence interval of the national average.

Panel (b) looks at relative mobility. The points indicate the estimated rank-rank slope which follows from a regression of child rank on father rank for each commuting zone separately. Ranks are defined according to the national income distribution. The vertical line indicates the $95 \%$ confidence interval. Commuting zones are ordered by relative mobilit 35 estimates. On the left are commuting zones with highest relative mobility estimates, on the commuting zones with lowest relative mobility estimates. A higher slope means lower relative mobility. The horizontal line depicts the national average and dashed horizontal line the $95 \%$ confidence interval of the national average. 


\section{Correlates}

In this section we aim to shed light at correlates of intergenerational mobility. First, we look at regional correlates, such as GDP per capita or inequality. Finally, we look at individual characteristics that correlate with increased probability of climbing up the income ladder.

\subsection{Regional Correlates}

How are absolute and relative mobility related? Figure 7 gives an answer to that question. Cantons with high relative mobility (and thus low rank-rank-slope) have in general higher absolute mobility. There is an interesting pattern: Cantons from the French or Italian language area tend to have lower absolute, but higher relative mobility (colored in blue) than in German-speaking cantons. ${ }^{15}$ Thus, French- or Italian-speaking areas are more equal in terms of opportunities, but the expected income for children from poor parents is lower. Different culture could be an explanation for this finding. However, those cantons also differ in a lot of other aspects, thus we do not dare to draw conclusions here.

Economic activity is an obvious suspect for cantonal differences in mobility. Figure 8 shows how mobility is related to GDP per capita averaged over the years 2012 to 2016 . In general, Panel (a) shows that higher economic activity is correlated with higher absolute mobility and Panel (b) shows the same for relative mobility.

Lastly, we are interested in the relationship between inequality and upward mobility. We investigate this relationship in Figure 9 by plotting the mobility estimates against income inequality for each canton. Usually this exercise is done on a country base and yields the so called «Great-Gatbsy-curve»: It claims that countries with high inequality have lower upward mobility (Corak and Heisz, 1999). We find some evidence for a positive relationship in Panel (a), in which cantons are the unit of observation. However,

\footnotetext{
${ }^{15}$ Cantons «GR» and «BE» also have a considerable share of non-German language areas.
} 


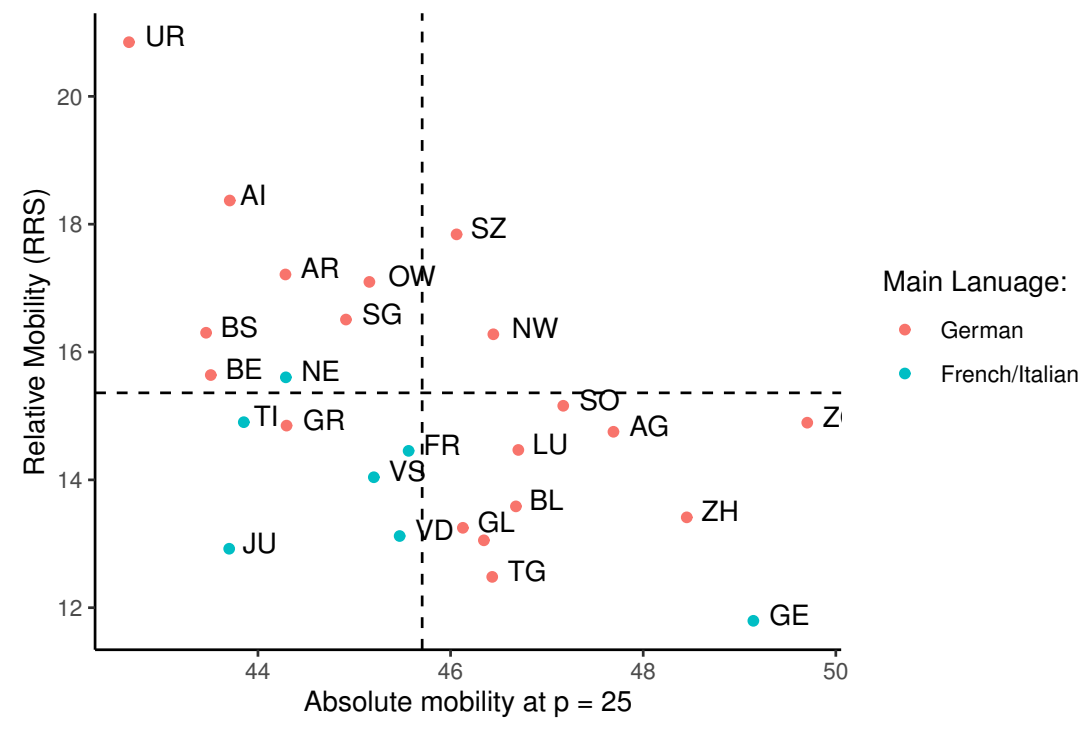

Figure 7: Absolute and Relative Mobility

Notes: This figure plots relative against absolute mobility on a canton level. The dashed lines represent the national average. In general, cantons with high relative mobility (low RRS) also have higher absolute mobility. This pattern is also observed in Sweden (Heidrich, 2017). However, cantons from French- and Italian-speaking areas deviate from this pattern: They have high relative mobility, but low absolute mobility. The cantons «BE» and «GR», that are also close to the lower left corner, inhabit regions with non-German speaking areas. 


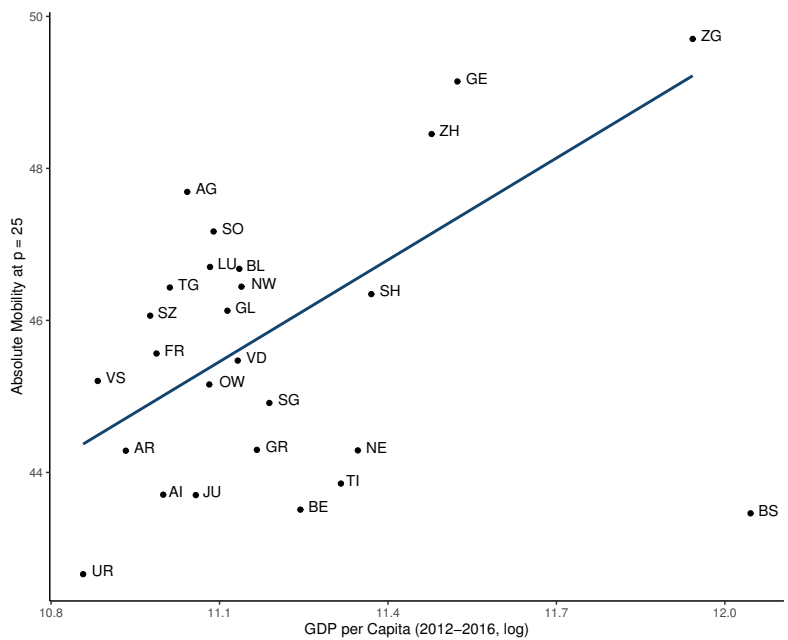

(a) Absolute Mobility

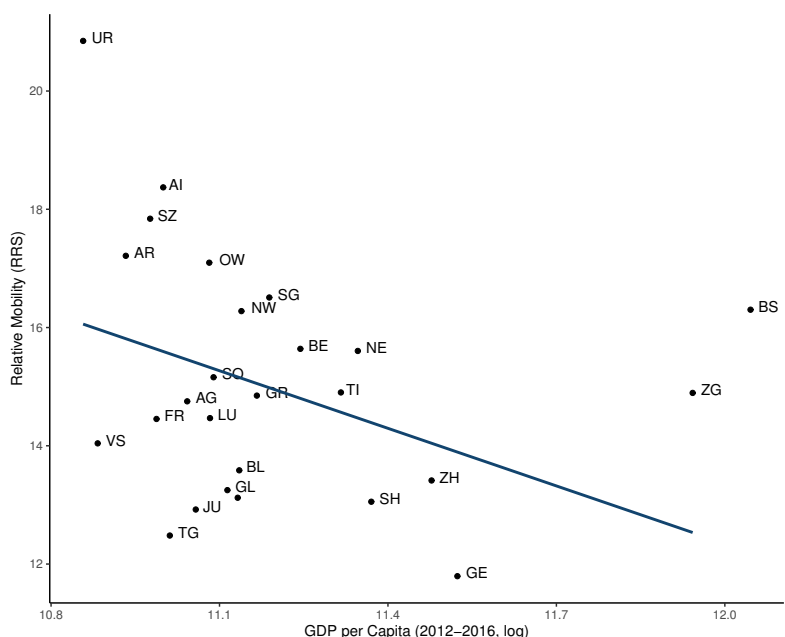

(b) Relative Mobility

Figure 8: GDP per Capita and Mobility

Notes: The figures relate intergenerational mobility of cantons with GDP per capita. GDP per capita is averaged over the years 2012 to 2016 and logarithmized. Panel (a) shows absolute mobility at $p=25$. Higher economic output per capita is associated with higher absolute mobility. However, some cantons deviate from the pattern, such as «BS». Panel (b) uses a relative mobility measure. Cantons with higher GDP per capita have on average higher relative mobility (thus lower RRS).

predictive power of this relationship is weak. In Panel (b), labor market regions are the unit of observation. Here, we find no relationship between inequality and upward mobility. To sum up, we find no convincing evidence for the existence of a «Great Gatbsy-Curve» within Switzerland.

\subsection{Personal and Family Characteristics}

In this section, we shed light on the individual determinants of upward mobility. We take advantage of our data which allows us link individual upward mobility information directly to individual characteristics.

Table 7 tests which personal characteristics are linked to upward mobility. We restrict the sample to children with a father in the bottom quintile of the income distribution. In column (1) are children who make it to rank 80 («the climbers») or more of the income distribution, whereas column 2) shows children that reach a rank below 80 («the stayers»). 


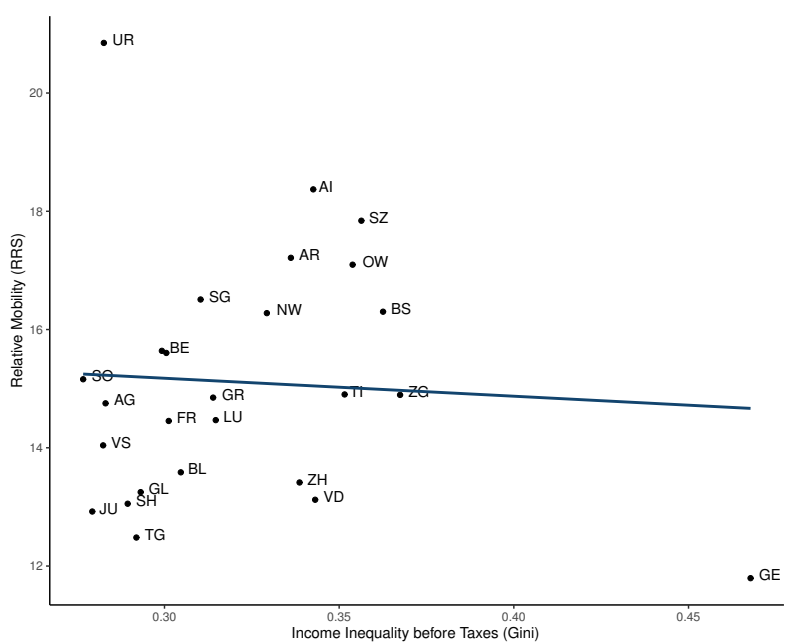

(a) Cantons

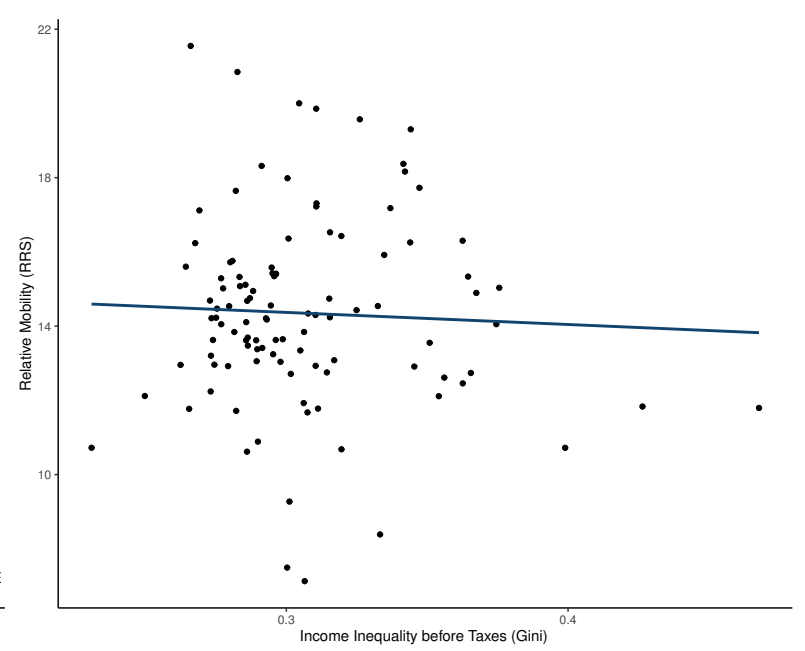

(b) Labor Market Regions

Figure 9: «Great Gatsby» Curve: Income Inequality and Upward Mobility

Notes: The two figures show how relationship between income inequality and relative mobility. Income inequality (Gini) is based on father's income. In left panel (a) the observations are on a cantonal level. Higher inequality is weakly associated with lower relative mobility (RRS). In panel (b) the unit of observation is labor market region. Here, no relationship is visible.

Column (3) shows difference and indicates if the difference is significant. Strikingly, among the climbers, only $25 \%$ are female. Furthermore, having more than one sibling is associated with lower upward mobility.

\section{Robustness}

In this section we evaluate the robustness of our mobility results. We first test how our national mobility estimates depend on alternative income definitions. This is important because two biases can occur when income is improperly defined: Attenuation and lifecycle bias. We continue by evaluating the stability of the rank-rank slope when family income is used instead of father income. Then, we analyze whether our estimates are stable when recoding missing values and non-labor earnings. In addition, we also test whether our regional results are robust to different location specifications. Finally, we provide evidence that our results are not severely affected by different regional price levels. 
Table 7: Personal Characteristics and Upward Mobility

\begin{tabular}{lcccc}
\hline \hline & $\begin{array}{c}(1) \\
\text { Rank }>80 \\
\text { «Climbers» }\end{array}$ & $\begin{array}{c}(2) \\
\text { Rank }<80 \\
\text { «Stayers» }\end{array}$ & $\begin{array}{c}(3) \\
\text { Diff } \\
\text { mean }\end{array}$ & $\begin{array}{c}(4) \\
\text { Full Sample }\end{array}$ \\
\hline Daugther & 0.248 & 0.525 & $0.277^{* * *}$ & 0.489 \\
Only Child & 0.099 & 0.089 & $-0.011^{* * *}$ & 0.081 \\
1 Sibling & 0.423 & 0.365 & $-0.058^{* * *}$ & 0.480 \\
2 Siblings & 0.272 & 0.284 & $0.011^{* *}$ & 0.291 \\
3 and more siblings & 0.206 & 0.263 & $0.057^{* * *}$ & 0.148 \\
Youngest Sibling & 0.545 & 0.524 & $-0.022^{* * *}$ & 0.553 \\
Middle Sibling & 0.108 & 0.136 & $0.028^{* * *}$ & 0.097 \\
Oldest Sibling & 0.562 & 0.542 & $-0.020^{* * *}$ & 0.555 \\
Twins & 0.015 & 0.016 & 0.001 & 0.016 \\
Mother's Age at Birth & 27.758 & 26.975 & $-0.783^{* * *}$ & 27.384 \\
Father's Age at Birth & 31.376 & 30.537 & $-0.838^{* * *}$ & 30.096 \\
Oldest Son & 0.383 & 0.236 & $-0.147^{* * *}$ & 0.261 \\
Oldest Daughter & 0.123 & 0.258 & $0.135^{* * *}$ & 0.249 \\
Father Single & 0.003 & 0.005 & $0.002^{* * *}$ & 0.002 \\
Mother Single & 0.005 & 0.006 & $0.001^{*}$ & 0.003 \\
Mother Married & 0.723 & 0.718 & -0.005 & 0.837 \\
Mother Widowed & 0.006 & 0.008 & $0.002^{* *}$ & 0.005 \\
Mother Divorced & 0.266 & 0.268 & 0.002 & 0.155 \\
Father Widowed & 0.002 & 0.003 & $0.001^{* * *}$ & 0.002 \\
Father Divorced & 0.237 & 0.243 & 0.006 & 0.122 \\
\hline Observations & 16,024 & 115,111 & 131,135 & 720,306 \\
\hline \hline Colys 1 shows & & & & \\
\hline
\end{tabular}

Notes: Columns 1 shows how «climbers» differ from «stayers». «Climbers» are children from the bottom quintile, who make it to the top quintile. «Stayers» are children from the bottom quintile that end up below rank 80 in the income distribution.

\subsection{Attenuation Bias}

Attenuation bias arises when transitory income shocks are not filtered out. This will attenuate the correlation between child and parents' earnings, leading to upward biased estimates of mobility. It is easy to see when using a single point in time (Solon, 1992). If transitory fluctuations are not serially correlated, averaging income across more years of observations, eases the attenuation bias (Solon, 1992; Mazumder, 2005).

To understand whether our estimates suffer from such attenuation bias, we vary the 


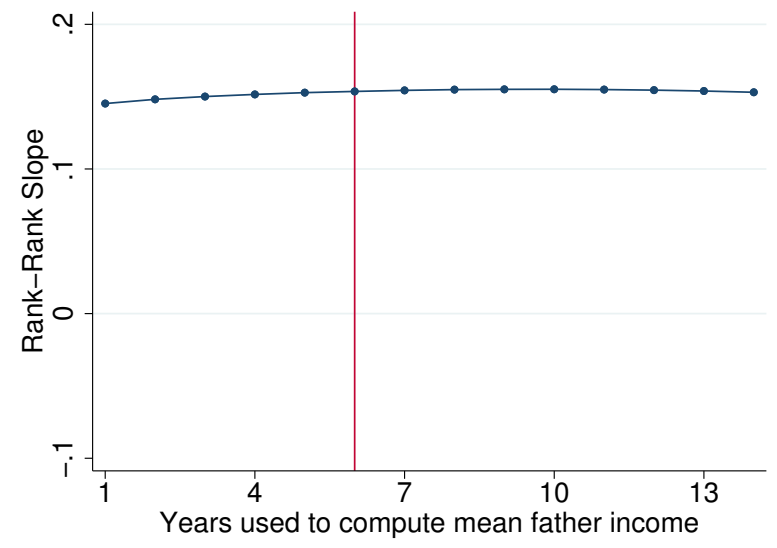

(a) RRS by Number of Years of Father Income

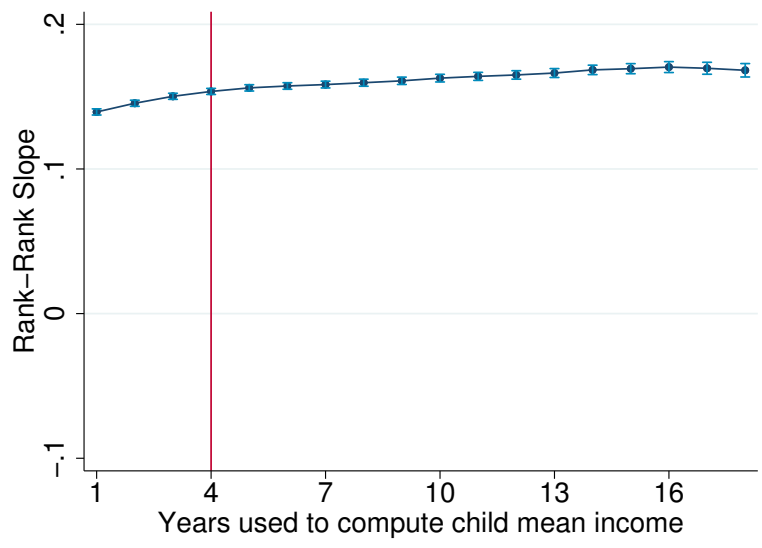

(b) RRS by Number of Years of Child Income

Figure 10: Robustness of Rank-Rank Slope Estimates: Attenuation Bias

Notes: In this figure we asses the robustness of the rank-rank slope to changes in the number of years used to measure father income (Panel a) and child income (Panel b). Fathers are ranked relative to other fathers of children in the same birth cohort. Children are ranked relative to other children in the same birth cohort.

number of years used to calculate mean fathers' income. Figure 10 Panel (a) shows the results from OLS regression of child and father rank varying the number of years over which we aggregate father mean income. We start with one year, the year when the child is 15 , to fourteen years, the years when the child is between 15 and 28 .

In our baseline estimates, we measure father's mean income when the child is between 15 and 20. Thus income is averaged across six years. In the graph the baseline estimate corresponds to the vertical line. The rank-rank slope based on one year data is 0.144 , which is lower than the rank-rank slope based on six years of data (0.152). This attenuation bias is much smaller than the one encountered by Solon (1992). His IGE estimates were 0.3 for a single year and 0.4 when using a five-year average. Mazumder (2005) reports that even five-year averages suffers from attenuation bias. However, we found that the rank-rank slope is virtually unaffected by adding more years of observations beyond six years. The rank-rank slope is 0.152 when we use 12 years of observations and 0.152 when we use 16 years.

The quality of our data and the rank-rank specification lead so stable estimates. The 
magnitude of the attenuation bias is comparable to the one found by Chetty et al. (2014a). They noticed an increase of $6.6 \%$ in the rank-rank slope, when five years of observations were used instead of a single year and nearly no changes in estimates when adding more years beyond five years.

Panel (b) tests how robust our estimates are to the number of years used to average child's income. The first point uses only the year when the child is 30 years old. This yields a rank-rank-slope of 0.138 . The vertical line correspond to the baseline specification with a rank-rank-slope of 0.152. Beyond this point, the number of cohorts is decreasing in the number of years. This is because in the core sample we can observe income for every cohort up to the age 33. The rank-rank-slope in the last point is 0.167 , the sample includes only the 1967 and 1970 cohorts and uses mean child income between the age of 30 and 47, 17 year average. The rank-rank slope increases when we aggregate child income over a larger time span, however the magnitude of the bias is reasonable. Moreover, the bias includes also part of the life-cycle bias, as children are on average older. Even with this «upper-bound» estimate, Switzerland would rank among the countries with the highest relative mobility.

\subsection{Life-Cycle Bias}

Life-cycle bias arises when income measured at the life-cycle stage systematically deviates from lifetime income. This might be the case when child income is measured earlier in their working life than their parent's income or when only a short snapshot of lifetime income is used. Life-cycle bias imposes a danger to understate income more for those with steeper income profiles, like the more educated. This can therefore lead to overestimated mobility.

Figure 11 evaluates the sensitivity of our baseline estimates to changes in age at which child income is measured. We plot the coefficients of separate rank-rank-slopes by varying the age at which a child incomes are measured for three samples. Father income is measured when the child is between the age of 15 and 20. Fathers are ranked relative to 


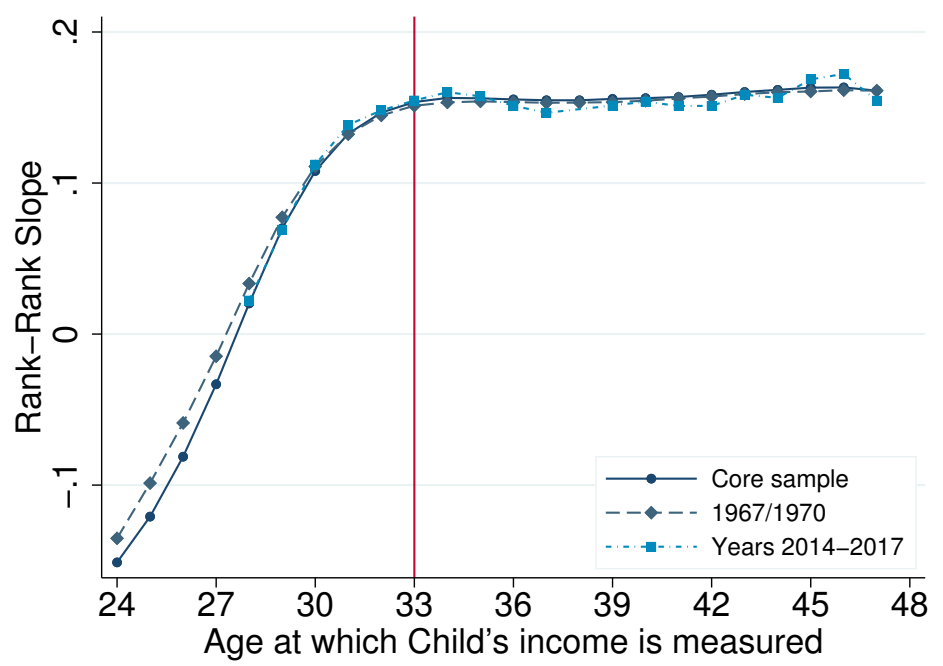

Figure 11: Life-Cycle Bias

Notes: This figure assesses the robustness of the rank-rank slopes estimates. For the baseline estimates, father income is averaged over the years when the child is between 15 and 20 years old. Father rank is defined relative to other fathers of children born between 1969 and 1984. Child mean income is the average income when the child is between the age 30 and 33. Child rank is defined relative to children in the same birth cohort. This corresponds to the point at age 33. The first point corresponds to the rank-rank slope when child mean income is averaged over the ages 21 and 24 . The last point uses average mean income between age 44 and 47 and is only observable for the 1969 and 1970 cohorts. Mean father rank is defined according to father income of children born in those cohorts. The dashed line plots the rank-rank slope coefficients by varying the age at which child income is measured only for the 1969 and 1970 cohorts. The dotted line plots the rank-rank slope coefficients when income is measured in the year 2014 to 2017.

other fathers of children in the same birth cohorts. Child incomes are averaged across four years, at different ages up to the age 47 . In the first point, the mean income is averaged over the age 21 and 24 . The straight line plots the coefficient of the core sample, the vertical line shows the baseline estimates. As before, beyond that point the number of cohorts decreases in child age. Around the age of 33 - which is defined as the mean of age 30 to 33 -, the rank-rank slope is fairly stable. This means that life-cycle bias disappears should not be an issue for our estimates.

When varying the age at which a child incomes are measured, we implicitly vary the number of cohorts and the calendar years at which child income is measured. However, we get similar results if we keep calendar year 2017 fixed and vary the cohorts, and if we restrict the sample to the 1967 to 1970 cohorts. The dashed line shows the RRS for 
the 1967 and 1970 cohorts, for which we observe income up to age of 47 . The dotted line reports the coefficients, keeping calendar year fixed at 2014 to 2017 and varying the cohorts.

A similar bias emerges if a father's income is measured too early or too late. In Table 8, we evaluate the robustness of our estimates to the age at which father income is measured. We also report the coefficient of the rank-rank slope when father's income is measured at 45. For a subset of cohorts, our data allow us to measure father's income when the child is very young. We also want to test whether financial resources during early childhood matter more for child outcomes than resources at later ages of the childhood. Therefore, we restrict our sample to the cohorts from 1979 to 1981. Then, we measure father's income when the child is between three and eight, and between nine and fourteen years old. The estimates reveal virtually no variation with father age between 30 and 50 years old.

\subsection{Location Choice}

In the main specification we use the mother's municipality in 2010 to approximate childhood location. This is because we do not have panel information on the exact location until 2010. However, we know when a person arrived in a specific municipality in 2010 and in which municipality a person was born. The municipality of birth is usually the location of the hospital, in which the mother gave birth. For our sample, born between 1967 and 1984, the hospital is usually in the same county (Bezirk) in which parents live.

We use mother's location in 2010 as an approximation of the location in which the child grew up. In 2010, $74.9 \%$ of mothers still live in the same municipality as in the year $1994 .{ }^{16}$ Furthermore, $81 \%$ of mothers live in the canton in which they gave birth to the child, while «only» $68 \%$ of children live in their birth canton. We do not use father's location because in case of a divorce children usually spend most time with their mother. The

\footnotetext{
${ }^{16}$ In 1994, the mean cohort of our sample (1967 to 1984) is 19 years old and thus likely to live in the same municipality as their mother.
} 
Table 8: Relative Mobility Estimates for Different Samples

\begin{tabular}{ccc}
\hline & \multicolumn{2}{c}{ Intergenrational correlation } \\
\cline { 2 - 3 } & Rank-Rank-Slope & IGE \\
$(2)$ & $(1)$ & $(2)$ \\
\hline
\end{tabular}

A. Baseline

Core Sample: 1969-1984

$0.154 \quad(0.0011) \quad 0.142 \quad(0.0015)$

B. Alternative samples

\begin{tabular}{lllll}
\hline Male Children & 0.189 & $(0.0015)$ & 0.121 & $(0.0016)$ \\
Female Children & 0.159 & $(0.0015)$ & 0.169 & $(0.0025)$ \\
Swissborn & 0.155 & $(0.0011)$ & 0.148 & $(0.0016)$ \\
Immigrants Children & 0.101 & $(0.0162)$ & 0.079 & $(0.0184)$
\end{tabular}

C. Alternative Cohorts

\begin{tabular}{lllll}
\hline Birth cohorts 1982-84 & 0.156 & $(0.0024)$ & 0.132 & $(0.0029)$ \\
Birth cohorts 1979-81 & 0.153 & $(0.0025)$ & 0.130 & $(0.0031)$ \\
Birth cohorts 1975-78 & 0.151 & $(0.0023)$ & 0.140 & $(0.0033)$ \\
Birth cohorts 1972-74 & 0.158 & $(0.0027)$ & 0.166 & $(0.0044)$ \\
Birth cohorts 1967-71 & 0.153 & $(0.0021)$ & 0.163 & $(0.0038)$
\end{tabular}

D. Varying Child Age

\begin{tabular}{llllll}
\hline Birth cohorts 1979-81 & Child age 33-36 & 0.149 & $(0.0025)$ & 0.141 & $(0.0035)$ \\
Birth cohorts 1975-78 & Child age 36-39 & 0.151 & $(0.0023)$ & 0.172 & $(0.0037)$ \\
Birth cohorts 1972-74 & Child age 40-43 & 0.160 & $(0.0027)$ & 0.212 & $(0.0049)$ \\
Birth cohorts 1969-71 & Child age 43-46 & 0.163 & $(0.0021)$ & 0.224 & $(0.0039)$
\end{tabular}

E. Varying Father Age

\begin{tabular}{lccccc}
\hline Birth cohorts 1979-81 & Child age $3-8$ & 0.159 & $(0.0025)$ & 0.157 & $(0.0038)$ \\
Birth cohorts 1979-81 & Child age $9-14$ & 0.158 & $(0.0025)$ & 0.155 & $(0.0036)$ \\
Core sample & Father age 40-45 & 0.153 & $(0.0012)$ & 0.163 & $(0.0019)$ \\
Core sample & Father age 45-50 & 0.155 & $(0.0011)$ & 0.146 & $(0.0016)$
\end{tabular}

F. Alternative Income Definitions

\begin{tabular}{llllll}
\hline Recoding non labor income to 0 & 0.144 & $(0.0011)$ & 0.146 & $(0.0017)$ \\
Excl. Missing Incomes & & 0.159 & $(0.0012)$ & 0.142 & $(0.0014)$ \\
Excl. Missing Incomes & Non-labor earnings to 0 & 0.146 & $(0.0012)$ & 0.145 & $(0.0016)$ \\
\hline
\end{tabular}

Notes: Standard errors in parenthesis. Ranks are redefined within sub-sample.

This table reports the baseline estimates and the results of OLS regressions of a measure of child income on a measure of father's income for several samples. Column (1) reports the coefficient of the rank-rank slope and standard errors in parentheses, column (2) report the IGE coefficient and the standard error in parentheses. Panel A, shows the baseline estimates. The sample comprises children born between 1967 and 1984. Father's income is averaged over the years when the child is 15 and 20. Child income is measured between the age 30 and 33. Children are ranked relative to other children in the same birth cohort. Fathers are ranked relative to other fathers with children in the 1967 to 1984 cohorts. Non-labor earnings are included, and we assigned zero income to individuals with missing income. The IGE specification corresponds to the specification 1 in Table A3. Panel (b) shows the estimates for four sub-samples, the rank is always defined at the national income distribution but only for the sub-sample. In row 2 , male children are ranked relative to other male children in the same birth cohorts and fathers are ranked relative to other fathers in this sub-sample. Panel (b) provides the estimates when alternative cohorts are used. Panel (d) shows the results when 45 mean child income is measured later in the age than in the baseline. Panel (e) evaluates the robustness of the estimates when we differ father's age. Panel (f) provides the results for alternative income definitions. 
propensity to change locations is relatively low in Switzerland. For example, Figure 13 — in the next section - shows that $50 \%$ of the children live less than $16 \mathrm{~km}$ from their mother's place when being an adult.

The general geographic pattern that we show in Section 7 does not depend on the location specification. Figure 12 shows relative and absolute mobility for each canton with different location specifications. Birth location is the place of birth of the child, mother's location is the municipality of residence of the mother in 2010 and mother's location 1994 is restricted to only the observations for those mother's who arrived in the municipality in 2010 in 1994. The differences are mostly insignificant. However, there is one exception: the half cantons Basel Stadt (BS) and Basel Land (BL). Those are so-called half cantons and count together as one canton. It is likely that many births took place in the more urban canton BS as there is a large hospital. Therefore, the municipality of birth is a bad proxy in those cantons. The two mother's location specifications are also similar in this canton. 


\subsection{Regional Deflator}

Our regional mobility estimates could be affected by differences in purchasing power. Purchasing power is likely to vary between regions in Switzerland. Regional deflation might therefore affect the ranks of the parents and children in the national income distribution. In mountainous regions, prices might be lower and a given nominal income might be valued higher than in urban areas.

Although we do not have a regional deflator at our disposal to test the impact, we argue that regional deflation is unlikely to have a large impact on our results. We draw from previous studies in Italy and the US. Both countries have large differences in purchasing power across regions. However, regional deflation only had a minor effect on intergenerational estimates (Acciari et al., 2019; Chetty et al., 2014a). This is mainly due to the fact, that most children live close to their parent's place, likely the place where they grew up. Therefore, regional deflation does not change the correlation between child and parent income rank strongly.

Figure 13 shows the distribution of distances of a child in 2010 from their mother's place in 2010 and from the municipality they were born. 50\% of children live closer than 16 $\mathrm{km}$ from their mother's place.

\section{Discussion}

In this paper, we use administrative income, census, and survey data to document intergenerational income mobility in Switzerland. We analyze how upward mobility varies across regions and which personal characteristics best describe children who move up the income ladder. Most importantly, we connect income mobility with educational mobility. In our baseline estimates we focus on children born in Switzerland between 1967 and 1984.

We find that intergenerational mobility is high in Switzerland. Relative mobility in terms 
of rank-rank slope (RRS) is 0.15 and in terms of intergenerational elasticity (IGE) 0.14. Absolute mobility looks at outcomes of children from parents with low income. Here, we find that a child with parents at rank 25 can expect to achieve rank 46. We also find sizeable gender differences among absolute mobility: $54 \%$ of sons earn more than their father at 40 , while only $18 \%$ of daughters earn more than their father. $12.9 \%$ of the children from the bottom quintile of the parent's income distribution end up in the top quintile. Taken together, almost all mobility estimates are higher than in the US, Italy, and Sweden.

Our analysis on education and upward mobility yields some remarkable findings. First, we show that educational mobility is low in Switzerland. The share of children receiving a university master's degree depends strongly on their fathers' income rank. This is surprising because one would expect high educational mobility in a country with high income mobility. Second, looking at non-university higher education, we find a much more equal distribution along parent's income rank. This suggest that «non-university educational mobility» is relatively high and is therefore likely to affect higher income mobility estimates. This confirms the often hailed permeability of the Swiss education system. In this system most students opt for vocational training after compulsory school, but still have the possibility to gain higher education later in life. Third, despite this permeability, a university master or gymnasium seem to be decisive to make it to the top. The odds of making it from the bottom to the top quintile are much higher with a gymnasium or university master degree. However, to make it above the median from the bottom quintile, non-university tertiary education seems more fruitful. Hence, it could conceivably be hypothesized that the strong educational vocation system is an effective «equalizer» and helps many children to climb the mountain at least up to the halfway station. However, to really climb the peak, academic education seems to be the strongest mountain guide. Because academic education does highly depend on father's income, Switzerland might miss some talents and, thus, loose some «Einsteins». ${ }^{17}$

\footnotetext{
${ }^{17}$ As a matter of fact, Switzerland actually brought up the only «real» Einstein. Albert Einstein grew up in Switzerland and actually had the chance to go to the gymnasium and obtain a university degree
} 
Income mobility varies across regions in Switzerland. This variation is similar to the one found Sweden, but lower than in the US or Italy (Chetty et al., 2014a; Heidrich, 2017; Acciari et al., 2019). Mobility is positively related to GDP per capita, which was also found in Italy. We further find that cantons with higher absolute mobility have higher relative mobility. An exception of this pattern are French- and Italian-speaking cantons. These cantons have a higher relative but lower absolute mobility. This is an interesting finding because it could point to culture as a determinant of upward mobility. Looking at the relationship between mobility and inequality, we find only a weak relationship on a cantonal level and no relationship at the commuting zone level. Thus, we find no evidence for a «Great Gatsby» curve in Switzerland. This is different to the US, where a «Great Gatsby» curve can be observed (Chetty et al., 2014a). Looking at personal characteristics that correlated with upward mobility, gender is the strongest predictor.

Measures on intergenerational mobility aim to provide a concise statistic of multidimensional transitions in income over generations. During this process, researchers have to decide which specifications are most meaningful. Therefore, there are some «researcher degrees of freedom» that could influence the estimates. In our core specification, we aimed to follow previous work to facilitate cross-country comparison. To make sure our estimates are not sensitive to certain specifications, we conducted several robustness checks.

In this study, we have documented intergenerational mobility in Switzerland. Although, we have shown potential determinants of upward mobility, we do not claim to have found causal pathways yet. If the vocational education system is indeed a booster for (medium) upward mobility, this could be a highly interesting policy option for countries with dangerously low intergenerational income mobility.

in Switzerland. Although we do not have his parent's rank in our sample, it is known that his parents were rather well-off. 


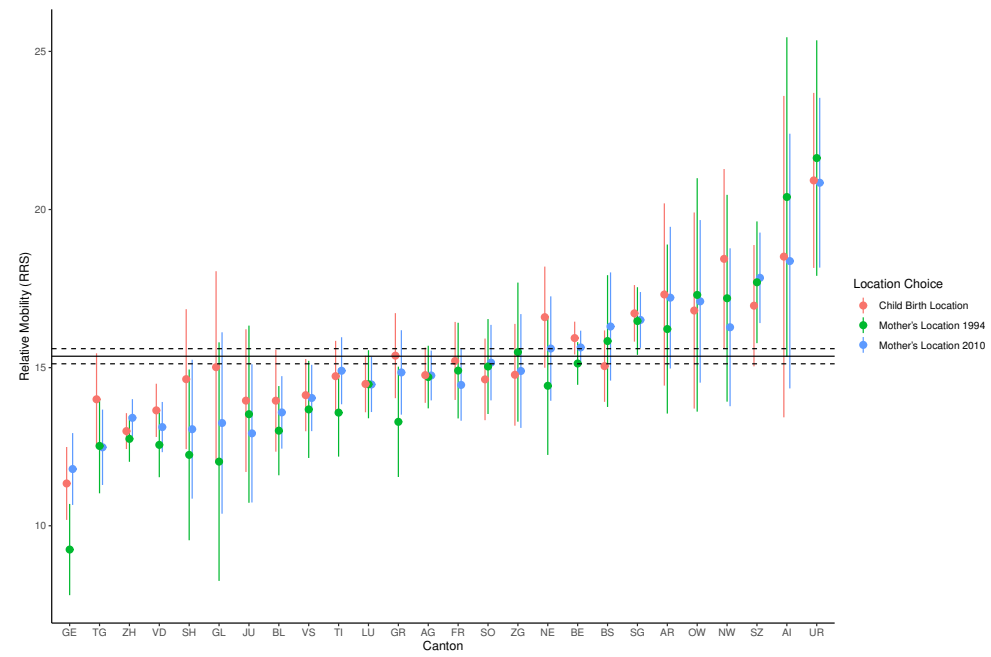

(a) Relative Mobility

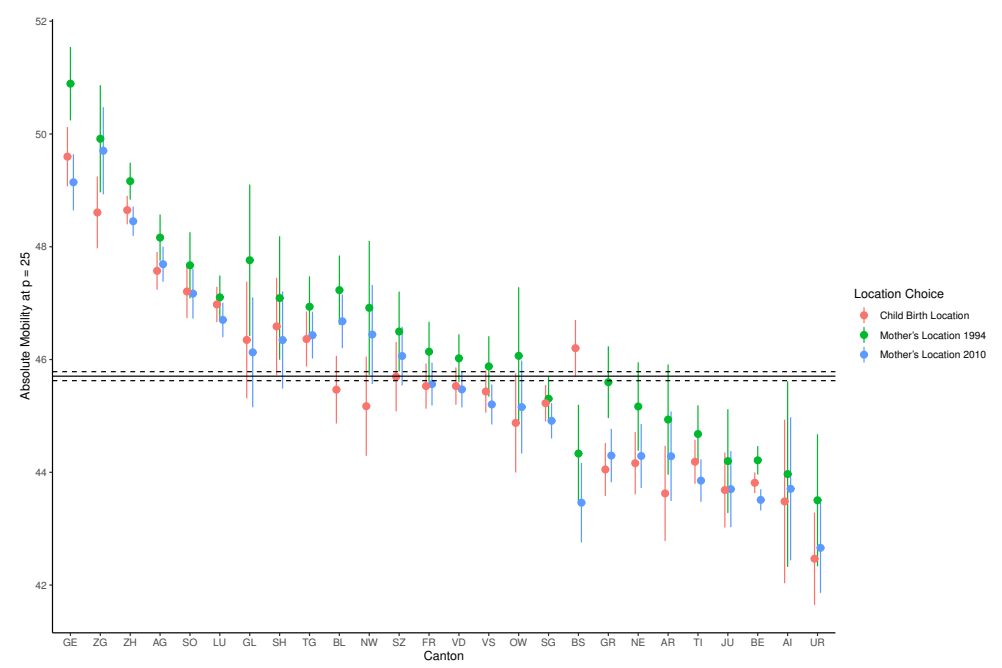

(b) Absolute Mobility

Figure 12: Robustness Location Specification

Notes: This figures shows the mobility estimates for different specifications of location. Mother's location 1994 is restricted to only those mother's who live in the same municipality 2010 as in 1994 (did not move). Place of birth refers to the municipality the child was born (usually the hospital location), mother's location refers to the location where the mother lived 2010). Apart from small cantons, mobility estimates do not significantly depend the specified location. 


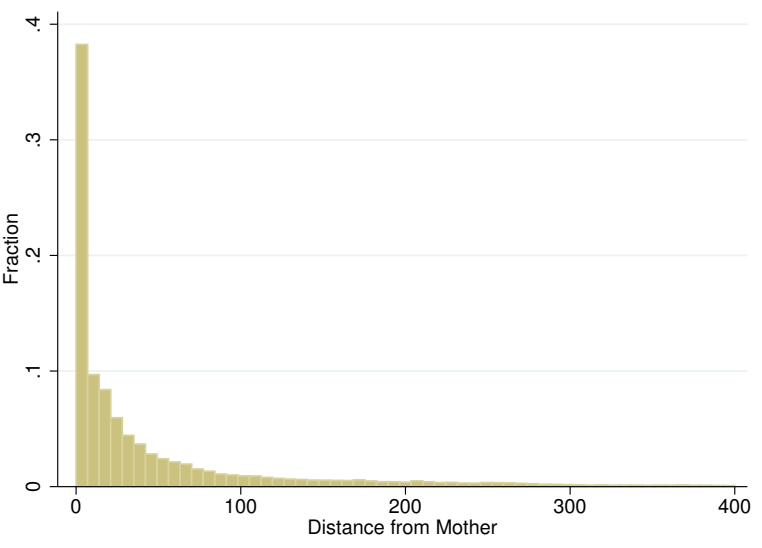

(a) Mother's Place

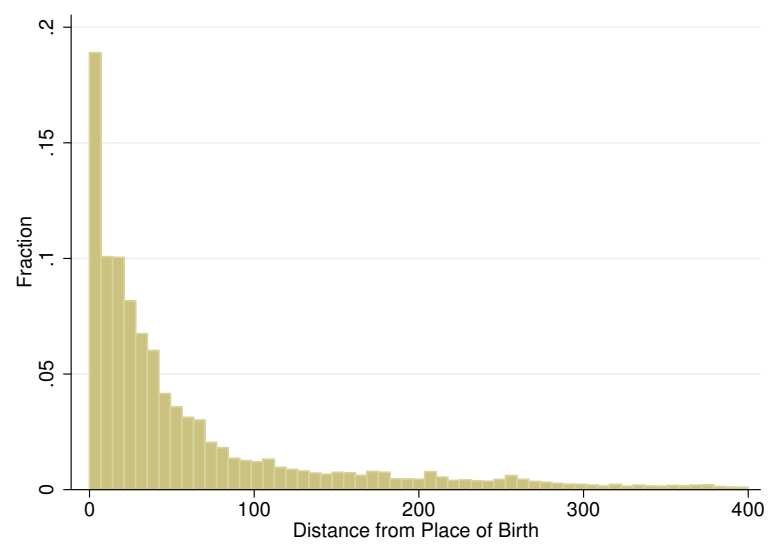

(b) Place of Birth

Figure 13: Distance from Places during Childhood (in km)

Notes: Panel (a): $50 \%$ of the children live closer than $16 \mathrm{~km}$ from their mother's place, $75 \%$ closer than $57 \mathrm{~km}$. Panel (b): $50 \%$ of the children live closer than $31 \mathrm{~km}$ from their place of birth, $75 \%$ closer than $80 \mathrm{~km}$. 


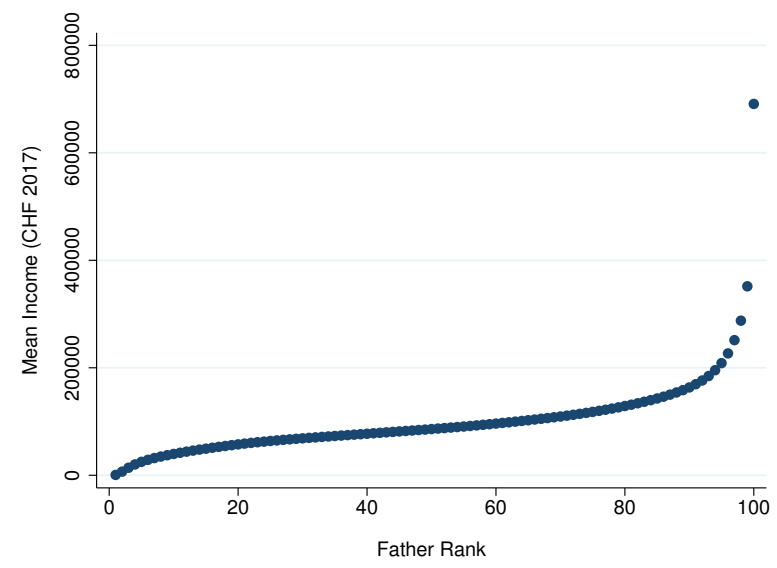

(a) Mean Income by Father Rank

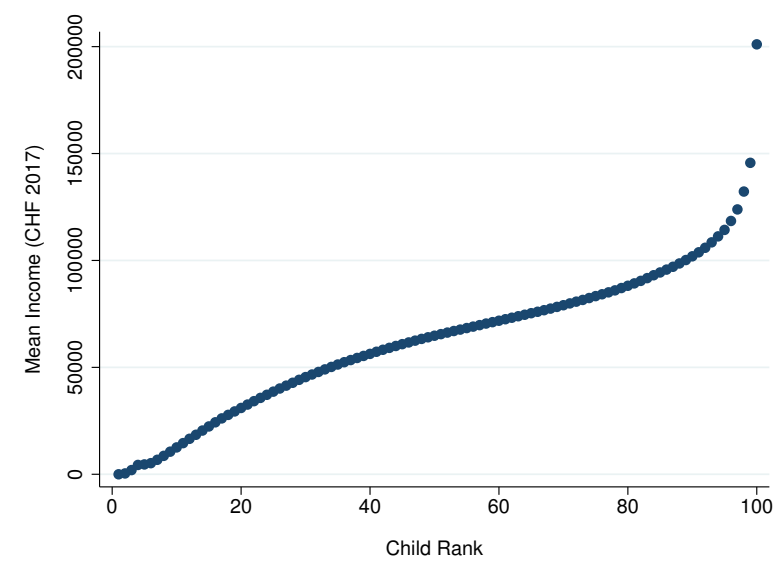

(b) Mean Income by Child Rank

Figure A1: Mean income by rank

Notes: The figure shows the mean income by rank of income among children (right) and their fathers (left). Please note that the y-axes have different scales. All incomes are in 2017 Swiss Francs.

\section{Appendix}


Table A1: Sample and Population Comparison

\begin{tabular}{lcccc}
\hline & $\begin{array}{c}\text { Population } \\
\text { Mean }\end{array}$ & $\begin{array}{c}\text { Core Sample } \\
\text { Mean }\end{array}$ & Diff. & Std.Err \\
& $(1)$ & $(2)$ & $(3)$ & $(4)$ \\
\hline 1. Age & 36.73 & 36.07 & $0.662^{* * *}$ & 0.0067 \\
2. Male (\%) & 50.60 & 51.00 & $-0.395^{* * *}$ & 0.0642 \\
3. Female (\%) & 49.40 & 49.00 & $0.395^{* * *}$ & 0.0642 \\
4. French (\%) & 24.59 & 20.02 & $4.578^{* * *}$ & 0.0542 \\
5. German (\%) & 70.93 & 75.94 & $-5.007^{* * *}$ & 0.0574 \\
6. Latin (\%) & 4.47 & 4.04 & $0.429^{* * *}$ & 0.0262 \\
7. Swiss (\%) & 64.71 & 99.11 & $-34.404^{* * * *}$ & 0.0522 \\
8. Swiss Born & 58.81 & 95.36 & $-36.541^{* * *}$ & 0.0553 \\
9. Immigrants (\%) & 3.08 & 0.45 & $2.634^{* * * *}$ & 0.0193 \\
10. Single (\%) & 36.71 & 44.21 & $-7.493^{* * *}$ & 0.0625 \\
11. Married (\%) & 55.79 & 49.91 & $5.887^{* * *}$ & 0.0639 \\
12.Non-Missing Income (\%) & 88.23 & 97.37 & $-9.133^{* * *}$ & 0.0367 \\
& & & & \\
Income measured at age 30-33 & & & & \\
13.Mean Income & 50161.75 & 61,136 & $-10974.157^{* * *} 53.3834$ \\
14.Top 99\% & 183,902 & 186,752 & $-2849.998^{* * * * 1093.2277}$ \\
15.Top 95\% & 139,627 & 144,392 & $-4764.458^{* * * *} 400.2513$ \\
16.Top 90\% & 121,223 & 126,758 & $-5534.189^{* * *} 231.7664$ \\
17.Top 80\% & 103,881 & 110,352 & $-6470.461^{* * *} 131.6285$ \\
18. Median & 49,916 & 62,441 & $-12525.265^{* * *} 3.7371$ \\
19. Bottom 20\% & 1,713 & 11,476 & $-9762.840^{* * * *}$ & 15.1889 \\
& & & & \\
\hline Obs. & $2,112,440$ & 849,543 & & \\
\hline Notes: $\% 0.05, *<0.019$ & & &
\end{tabular}

Notes: $\quad *<0.05, * *<0.01,{ }^{*} *{ }^{*}<0.001$

The amounts are in expressed in 2017 Swiss Francs. Column 1 shows the means of the full sample in Switzerland 2012. Column 2 shows the sample used in our analysis. 


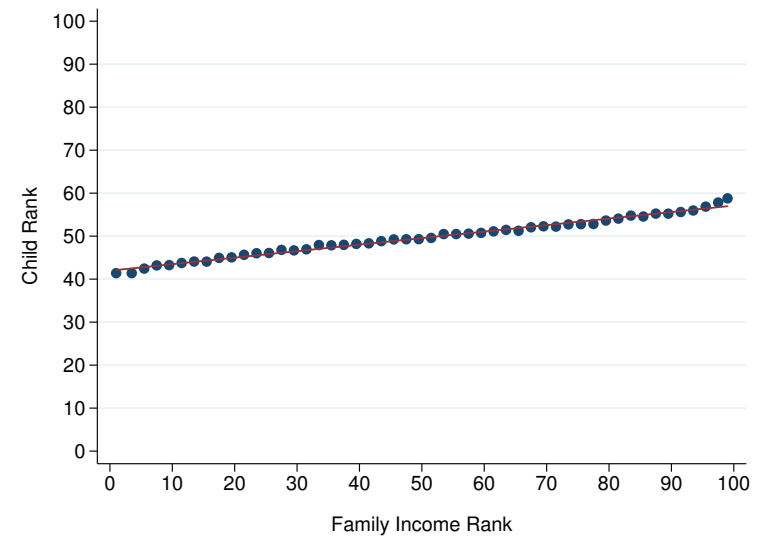

(a) Family Rank

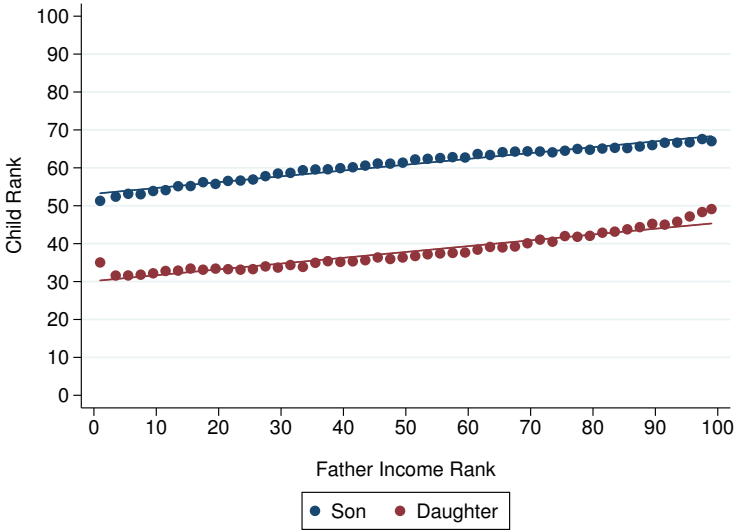

(b) Father's Rank by Gender of child

Figure A2: Alternative Rank-Rank Relationship

Notes: Panel (a): This graph uses family income rank instead of father income rank. To define family income rank, we take the mean of the average mother income and father income when the child is between 15 and 20. Families are ranked relative to other families with a child in the birth cohorts 1967 to 1984 . This yields a constant $=42.01$ and a slope of 0.151 . The $R^{2}$ is 0.02

Panel (b): This graph runs the regression child rank on father rank for sons and daughters individually. For daughters the constant is 30.5 and the slope 0.152 , the $R^{2}$ is 0.02 . For sons the constant is 53 and the slope 0.152 . The $R^{2}$ is 0.02 

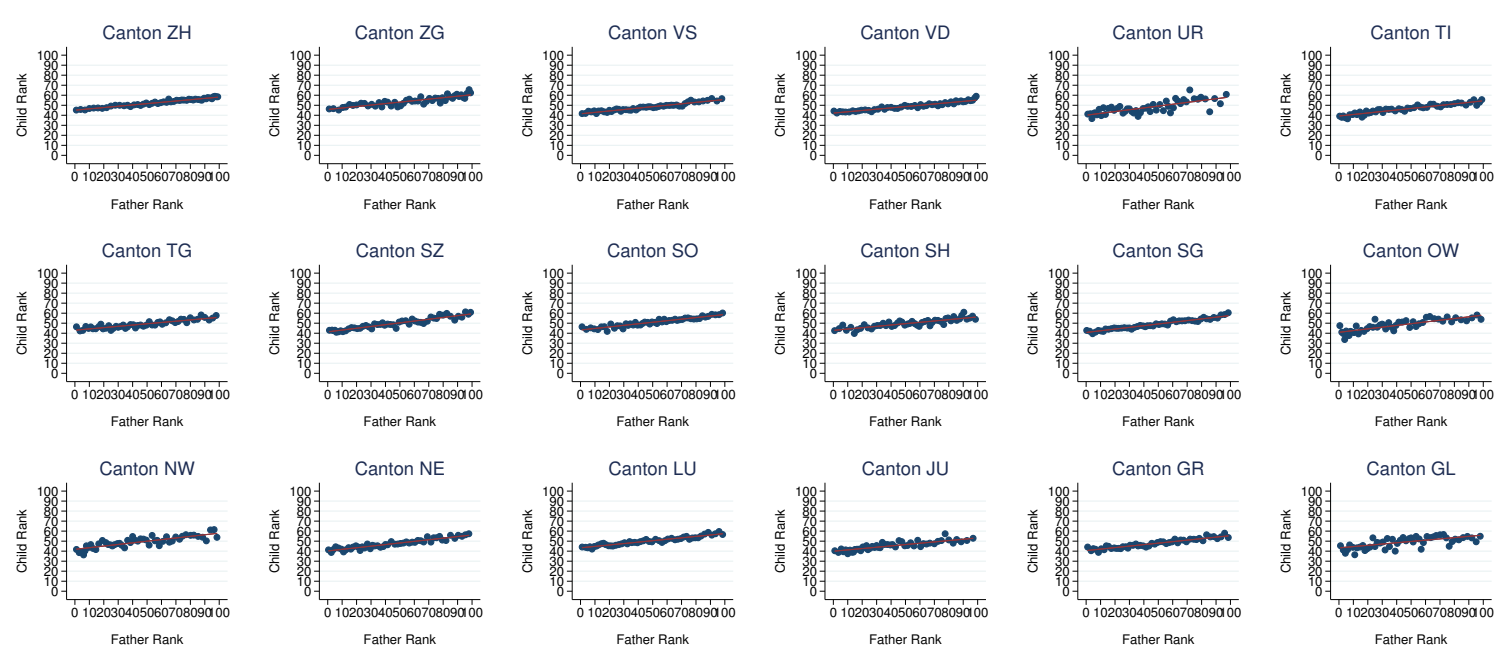

Father Rank
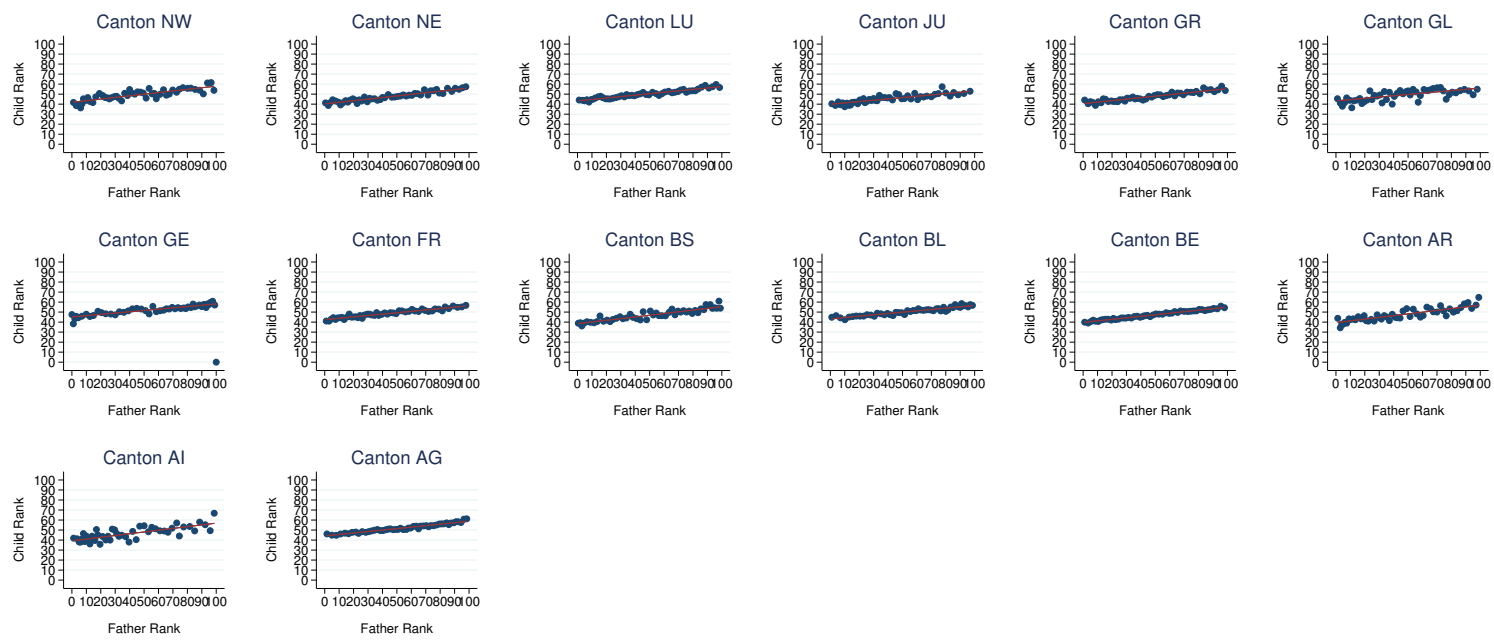

Figure A3: Rank-Rank Relationship by Canton

Notes: This graph shows the relationship between child and father rank for each canton separately. The ranks are assigned according the national income distribution. In all cantons, the relationship is linear. Smaller cantons, such as UR or AI, show more noise. 


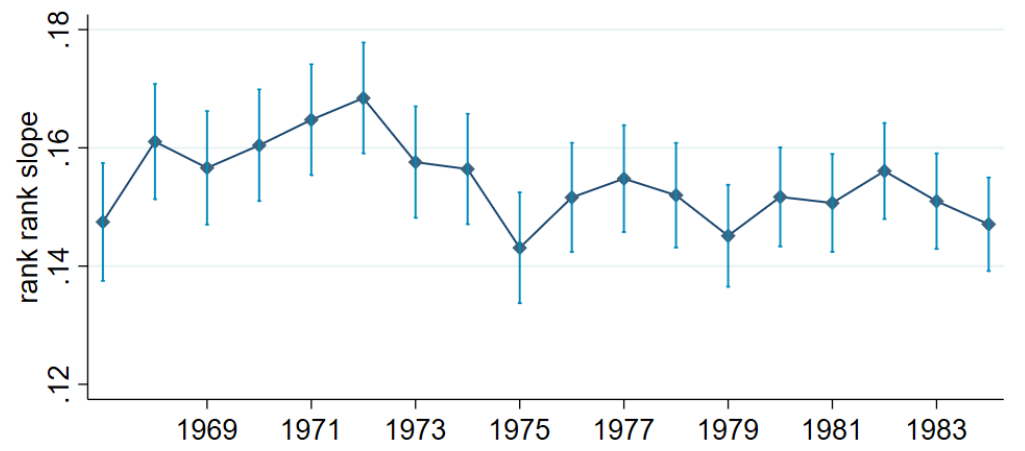

Figure A4: Rank-Rank Slope by Cohort

Notes: This figure plot the estimate and confidence interval of separate OLS regression of the child rank on father rank for every cohort in the core sample. Confidence int several samples. Child rank is defined relative to other children in the same birth cohort, and father rank is defined relative to other father with children in the cohort (e.g for the 1967 cohort, father are ranked relative to other father of children born in 1967. Child income is averaged across four years, from the age of 30 to the age of 33. Father income is measured when the child is between 15 and 20 . 
Table A2: Descriptives by cohort

\begin{tabular}{|c|c|c|c|c|c|c|c|c|c|}
\hline & \multicolumn{9}{|c|}{ Birth Cohort } \\
\hline & $\begin{array}{c}1967 \\
(1)\end{array}$ & $\begin{array}{c}1968 \\
(2)\end{array}$ & $\begin{array}{c}1969 \\
(3)\end{array}$ & $\begin{array}{c}1970 \\
(4)\end{array}$ & $\begin{array}{c}1971 \\
(5)\end{array}$ & $\begin{array}{c}1972 \\
(6)\end{array}$ & $\begin{array}{c}1973 \\
(7)\end{array}$ & $\begin{array}{c}1974 \\
(8)\end{array}$ & $\begin{array}{c}1975 \\
(9)\end{array}$ \\
\hline \multicolumn{10}{|l|}{ Child: } \\
\hline 1.Identified parents (\%) & 48.18 & 51.09 & 53.37 & 55.89 & 58.19 & 60.34 & 62.05 & 64.22 & 66.41 \\
\hline 2. Identified Mother (\%) & 75.26 & 76.35 & 77.45 & 78.14 & 79.10 & 79.58 & 79.97 & 80.80 & 81.94 \\
\hline 3. Identified Father (\%) & 55.76 & 58.55 & 60.49 & 62.81 & 64.80 & 66.67 & 68.17 & 70.12 & 71.98 \\
\hline 3.Child non missing income $(\%)$ & 94.98 & 95.54 & 95.94 & 96.35 & 96.50 & 96.63 & 96.86 & 97.18 & 97.34 \\
\hline 4.Swiss $(\%)$ & 99.52 & 99.51 & 99.51 & 99.42 & 99.35 & 99.30 & 99.19 & 99.12 & 99.16 \\
\hline 5.Immigrants (\%) & 0.30 & 0.33 & 0.36 & 0.41 & 0.45 & 0.52 & 0.56 & 0.59 & 0.47 \\
\hline 6.Swissborn (\%) & 96.71 & 96.67 & 96.71 & 96.55 & 96.44 & 96.55 & 96.28 & 96.20 & 95.89 \\
\hline 7.Single $(\%)$ & 21.79 & 23.08 & 24.71 & 26.14 & 27.56 & 29.23 & 30.81 & 33.51 & 35.58 \\
\hline 8.Married (\%) & 64.20 & 64.25 & 63.70 & 63.31 & 63.15 & 62.49 & 61.79 & 60.09 & 58.69 \\
\hline \multicolumn{10}{|l|}{ Father: Child is 15-20 } \\
\hline 9.Father Age & 46.76 & 46.79 & 46.90 & 46.98 & 47.03 & 47.07 & 47.18 & 47.27 & 47.36 \\
\hline 10.Father age at childbirth & 29.26 & 29.29 & 29.40 & 29.48 & 29.53 & 29.57 & 29.68 & 29.77 & 29.86 \\
\hline 11.Swiss Father (\%) & 96.58 & 96.58 & 96.60 & 96.40 & 96.28 & 96.35 & 96.17 & 95.89 & 96.01 \\
\hline 12.Foreign Father (\%) & 3.42 & 3.42 & 3.40 & 3.60 & 3.72 & 3.65 & 3.83 & 4.11 & 3.99 \\
\hline 13.Married Parents (\%) & 82.88 & 82.48 & 81.98 & 81.47 & 81.59 & 80.76 & 80.80 & 80.58 & 79.39 \\
\hline 14.Divorced Parents (\%) & 7.67 & 7.99 & 8.43 & 8.87 & 8.76 & 9.42 & 9.54 & 9.75 & 10.42 \\
\hline 15.Father Non-Missing Income (\%) & 99.39 & 99.45 & 99.43 & 99.44 & 99.41 & 99.47 & 99.47 & 99.41 & 99.40 \\
\hline 16.Father Mean Income & 95,136 & 96,446 & 97,920 & 99,506 & 101,167 & 101,996 & 102,604 & 101,790 & 103,870 \\
\hline 17.Father Median Income & 81,637 & 83,086 & 83,481 & 84,285 & 85,749 & 86,586 & 86,821 & 87,336 & 87,622 \\
\hline 18.Father Max Income & $4,868,039$ & $4,080,083$ & $18,187,300$ & $9,809,727$ & $3,777,495$ & $15,987,486$ & $19,217,652$ & $1,692,215$ & $24,327,504$ \\
\hline 19.Father Top $10 \%$ Income & 152,773 & 154,372 & 157,114 & 160,716 & 162,684 & 164,812 & 165,452 & 165,750 & 166,648 \\
\hline 20.Father Top 5\% Income & 193,833 & 196,409 & 198,670 & 205,534 & 210,221 & 212,178 & 213,077 & 213,749 & 212,980 \\
\hline 21.Father Top $1 \%$ Income & 353,477 & 352,665 & 358,165 & 368,964 & 382,805 & 378,531 & 386,678 & 373,812 & 394,161 \\
\hline Obs. & 41,624 & 43,340 & 43,914 & 44,596 & 45,307 & 44,512 & 43,982 & 44,255 & 43,677 \\
\hline
\end{tabular}


Table A2

(Continued)

\begin{tabular}{|c|c|c|c|c|c|c|c|c|c|}
\hline & \multicolumn{9}{|c|}{ Birth Cohort } \\
\hline & $\begin{array}{c}1976 \\
(1)\end{array}$ & $\begin{array}{c}1977 \\
(2)\end{array}$ & $\begin{array}{c}1978 \\
(3)\end{array}$ & $\begin{array}{c}1979 \\
(4)\end{array}$ & $\begin{array}{c}1980 \\
(5)\end{array}$ & $\begin{array}{c}1981 \\
(6)\end{array}$ & $\begin{array}{c}1982 \\
(7)\end{array}$ & $\begin{array}{c}1983 \\
(8)\end{array}$ & $\begin{array}{c}1984 \\
(9)\end{array}$ \\
\hline \multicolumn{10}{|l|}{ Child: } \\
\hline 1.Identified parents (\%) & 68.44 & 70.38 & 72.21 & 73.61 & 74.87 & 75.72 & 77.01 & 78.16 & 79.08 \\
\hline 2. Identified Mother (\%) & 83.29 & 84.01 & 84.98 & 85.87 & 86.43 & 86.82 & 87.39 & 87.91 & 88.46 \\
\hline 3. Identified Father (\%) & 73.77 & 75.61 & 77.10 & 78.29 & 79.27 & 79.86 & 80.87 & 81.90 & 82.55 \\
\hline 3.Child non missing income (\%) & 97.74 & 97.99 & 98.10 & 98.27 & 98.30 & 98.53 & 98.41 & 98.44 & 98.13 \\
\hline 4.Swiss $(\%)$ & 99.02 & 98.96 & 99.02 & 98.98 & 98.94 & 98.92 & 98.80 & 98.85 & 98.76 \\
\hline 5.Immigrants (\%) & 0.51 & 0.51 & 0.40 & 0.41 & 0.43 & 0.43 & 0.49 & 0.43 & 0.45 \\
\hline 6.Swissborn (\%) & 95.42 & 95.02 & 94.82 & 94.55 & 94.30 & 94.18 & 94.09 & 94.03 & 93.61 \\
\hline 7.Single (\%) & 39.05 & 42.74 & 46.52 & 51.22 & 55.97 & 61.24 & 67.08 & 72.71 & 78.57 \\
\hline 8.Married (\%) & 56.27 & 52.96 & 49.79 & 45.53 & 41.35 & 36.52 & 31.09 & 25.70 & 20.32 \\
\hline \multicolumn{10}{|l|}{ Father: Child is 15-20 } \\
\hline 9.Father Age & 47.52 & 47.71 & 47.83 & 47.98 & 48.04 & 48.14 & 48.23 & 48.33 & 48.49 \\
\hline 10.Father age at childbirth & 30.02 & 30.21 & 30.33 & 30.48 & 30.54 & 30.64 & 30.73 & 30.83 & 30.99 \\
\hline 11.Swiss Father (\%) & 95.99 & 95.89 & 95.90 & 95.92 & 95.72 & 95.69 & 95.65 & 95.55 & 95.46 \\
\hline 12.Foreign Father (\%) & 4.01 & 4.11 & 4.10 & 4.08 & 4.28 & 4.31 & 4.35 & 4.45 & 4.54 \\
\hline 13.Married Parents (\%) & 79.01 & 78.02 & 77.59 & 76.21 & 75.35 & 75.08 & 74.08 & 73.38 & 73.00 \\
\hline 14.Divorced Parents (\%) & 10.99 & 11.48 & 11.95 & 12.88 & 13.45 & 13.76 & 14.76 & 15.13 & 15.72 \\
\hline 15.Father Non-Missing Income (\%) & 99.40 & 99.46 & 99.42 & 99.40 & 99.37 & 99.37 & 99.12 & 99.04 & 99.03 \\
\hline 16.Father Mean Income & 102,657 & 102,788 & 101,089 & 100,634 & 99,686 & 99,798 & 100,034 & 100,963 & 101,756 \\
\hline 17.Father Median Income & 87,492 & 87,306 & 85,706 & 85,110 & 84,426 & 84,171 & 83,998 & 84,076 & 85,323 \\
\hline 18.Father Max Income & $5,206,477$ & $26,238,890$ & $26,740,082$ & $27,265,426$ & $7,200,414$ & $11,702,201$ & $14,749,844$ & $15,241,941$ & $15,098,658$ \\
\hline 19.Father Top $10 \%$ Income & 167,140 & 165,995 & 163,941 & 163,744 & 162,124 & 162,345 & 162,579 & 163,831 & 167,197 \\
\hline 20.Father Top 5\% Income & 214,089 & 213,374 & 211,500 & 213,516 & 212,486 & 214,158 & 214,885 & 219,412 & 221,863 \\
\hline 21.Father Top 1\% Income & 401,509 & 400,518 & 390,965 & 399,382 & 409,698 & 415,140 & 411,465 & 430,397 & 432,964 \\
\hline Obs. & 44,466 & 45,833 & 46,924 & 48,799 & 51,248 & 52,225 & 54,079 & 54,375 & 56,387 \\
\hline
\end{tabular}


Table A3: National Estimates

\begin{tabular}{|c|c|c|c|c|c|c|c|c|c|c|}
\hline & & (1) & $(2)$ & (3) & (4) & $\begin{array}{c}(5) \\
\text { Sample }\end{array}$ & (6) & $(7)$ & (8) & (9) \\
\hline Child's outcome & Parent's inc def & $\begin{array}{c}\text { Core } \\
\text { sample }\end{array}$ & $\begin{array}{l}\text { 1979-1981 } \\
\text { Cohorts }\end{array}$ & $\begin{array}{c}\text { Male } \\
\text { children }\end{array}$ & $\begin{array}{l}\text { Female } \\
\text { Children }\end{array}$ & $\begin{array}{l}\text { Foreign } \\
\text { Father }\end{array}$ & $\begin{array}{l}\text { Swiss } \\
\text { Father }\end{array}$ & $\begin{array}{l}\text { Teenagebirth } \\
\text { Children }\end{array}$ & $\begin{array}{c}\text { Fixed } \\
\text { age at } \\
\text { child birth }\end{array}$ & Married \\
\hline \multicolumn{11}{|l|}{ IGE: } \\
\hline $\begin{array}{l}\overline{\log } \text { individual income } \\
\text { excluding zeros }\end{array}$ & Log father income & $\begin{array}{c}0.142 \\
(0.0015)\end{array}$ & $\begin{array}{c}0.130 \\
(0.0031)\end{array}$ & $\begin{array}{c}0.121 \\
(0.0016)\end{array}$ & $\begin{array}{c}0.169 \\
(0.0025)\end{array}$ & $\begin{array}{c}0.100 \\
(0.0064)\end{array}$ & $\begin{array}{c}0.145 \\
(0.0016)\end{array}$ & $\begin{array}{c}0.134 \\
(0.0109)\end{array}$ & $\begin{array}{c}0.144 \\
(0.0026)\end{array}$ & $\begin{array}{c}0.143 \\
(0.0018)\end{array}$ \\
\hline $\begin{array}{l}\text { Log individual income } \\
\text { (recoding zeros to } 1 \text { ) }\end{array}$ & Log father income & $\begin{array}{c}0.093 \\
(0.0019)\end{array}$ & $\begin{array}{c}0.089 \\
(0.0036)\end{array}$ & $\begin{array}{c}0.073 \\
(0.0013)\end{array}$ & $\begin{array}{c}0.112 \\
(0.0034)\end{array}$ & $\begin{array}{c}0.065 \\
(0.0050)\end{array}$ & $\begin{array}{c}0.098 \\
(0.0020)\end{array}$ & $\begin{array}{c}0.072 \\
(0.0126)\end{array}$ & $\begin{array}{c}0.061 \\
(0.0016)\end{array}$ & $\begin{array}{c}0.051 \\
(0.0010)\end{array}$ \\
\hline $\begin{array}{l}\text { Log individual income } \\
\text { (recoding zeros to 1000) } \\
\text { RRS: }\end{array}$ & Log father income & $\begin{array}{c}0.136 \\
(0.0016)\end{array}$ & $\begin{array}{c}0.126 \\
(0.0032)\end{array}$ & $\begin{array}{c}0.109 \\
(0.0015)\end{array}$ & $\begin{array}{c}0.162 \\
(0.0026)\end{array}$ & $\begin{array}{c}0.084 \\
(0.0055)\end{array}$ & $\begin{array}{c}0.141 \\
(0.0017)\end{array}$ & $\begin{array}{c}0.113 \\
(0.0110)\end{array}$ & $\begin{array}{c}0.144 \\
(0.0027)\end{array}$ & $\begin{array}{c}0.139 \\
(0.0019)\end{array}$ \\
\hline Individual income rank & Father income rank & $\begin{array}{c}0.154 \\
(0.0011)\end{array}$ & $\begin{array}{c}0.153 \\
(0.0025)\end{array}$ & $\begin{array}{c}0.154 \\
(0.0014)\end{array}$ & $\begin{array}{c}0.153 \\
(0.0014)\end{array}$ & $\begin{array}{c}0.150 \\
(0.0059)\end{array}$ & $\begin{array}{c}0.154 \\
(0.0011)\end{array}$ & $\begin{array}{c}0.151 \\
(0.0081)\end{array}$ & $\begin{array}{c}0.153 \\
(0.0018)\end{array}$ & $\begin{array}{c}0.157 \\
(0.0012)\end{array}$ \\
\hline Individual income rank & Mother income rank & $\begin{array}{c}0.024 \\
(0.0010)\end{array}$ & $\begin{array}{c}0.024 \\
(0.0024)\end{array}$ & $\begin{array}{l}-0.006 \\
(0.0012)\end{array}$ & $\begin{array}{c}0.060 \\
(0.0013)\end{array}$ & $\begin{array}{c}0.033 \\
(0.0050)\end{array}$ & $\begin{array}{c}0.024 \\
(0.0010)\end{array}$ & $\begin{array}{c}0.040 \\
(0.0066)\end{array}$ & $\begin{array}{c}0.029 \\
(0.0016)\end{array}$ & $\begin{array}{c}0.051 \\
(0.0012)\end{array}$ \\
\hline Individual income rank & Family income rank & $\begin{array}{c}0.152 \\
(0.0011)\end{array}$ & $\begin{array}{c}0.152 \\
(0.0025)\end{array}$ & $\begin{array}{c}0.129 \\
(0.0014)\end{array}$ & $\begin{array}{c}0.177 \\
(0.0014)\end{array}$ & $\begin{array}{c}0.146 \\
(0.0057)\end{array}$ & $\begin{array}{c}0.152 \\
(0.0011)\end{array}$ & $\begin{array}{c}0.155 \\
(0.0078)\end{array}$ & $\begin{array}{c}0.152 \\
(0.0018)\end{array}$ & $\begin{array}{c}0.159 \\
(0.0012)\end{array}$ \\
\hline Observations & & 849543 & 152272 & 433253 & 416290 & 33925 & 815618 & 21765 & 308267 & 664796 \\
\hline
\end{tabular}

Notes: Each cell reports the coefficient from an OLS regression of a child's outcome on a measure of its family income. Column (1) uses the core sample, which includes all children (i) born in birth cohorts 1969 to 1989 (ii) for whom we have been able to link both parents (iii) whose mean income at age 30 to 33 is positive and (iv) whose mean parent's income when child is between 15-20 is non-negative. Column (2) reports the estimates for birth cohorts 1979 to 1981 . Columns (3) and (4) restrict the sample to male and female. Columns(5) and (6) limits the sample to children whose father is either foreign or Swiss. Column (8) estimates income mobility among children whose mother was between 13 and 19 years old at child birth. Column (8) limits the core sample to children whose father fall into a 5 -year window of median father age at time of child birth. Column (9) restricts the sample to children whose parents are still married in 2012 and live in the same household in 2012 . Child income is the mean of the individual income between age 30 to 33, while parent family income is the mean income when the child is between age 15 and 20. Individual earnings include wage earnings, self-employment earnings, unemployment insurance and disability benefits. Income percentile ranks are constructed by ranking all children relative to other children in the same birth cohort, and ranking parents relative to other parents in the core sample. Ranks are not redefined within sub-samples except in column (2). The number of observations correspond to the specification in row 4 . 
Table A4: Mean Child and Father Income by Rank

\begin{tabular}{|c|c|c|c|c|c|c|c|c|c|c|c|}
\hline Rank & $\begin{array}{l}\text { Child } \\
\text { Income }\end{array}$ & $\begin{array}{l}\text { Father } \\
\text { Income }\end{array}$ & Rank & $\begin{array}{l}\text { Child } \\
\text { Income }\end{array}$ & $\begin{array}{l}\text { Father } \\
\text { Income }\end{array}$ & Rank & $\begin{array}{l}\text { Child } \\
\text { Income }\end{array}$ & $\begin{array}{l}\text { Father } \\
\text { Income }\end{array}$ & Rank & $\begin{array}{l}\text { Child } \\
\text { Income }\end{array}$ & $\begin{array}{l}\text { Father } \\
\text { Income }\end{array}$ \\
\hline 1 & 0 & 693 & 26 & 37,243 & 64,911 & 51 & 63,548 & 86,637 & 76 & 82,834 & 119,365 \\
\hline 2 & 383 & 7,160 & 27 & 38,645 & 65,903 & 52 & 64,304 & 87,564 & 77 & 83,814 & 121,402 \\
\hline 3 & 1,515 & 14,574 & 28 & 40,017 & 66,872 & 53 & 65,062 & 88,492 & 78 & 84,831 & 123,558 \\
\hline 4 & 3,263 & 20,819 & 29 & 41,357 & 67,809 & 54 & 65,806 & 89,443 & 79 & 85,883 & 125,829 \\
\hline 5 & 2,891 & 25,504 & 30 & 42,659 & 68,699 & 55 & 66,542 & 90,412 & 80 & 86,990 & 128,207 \\
\hline 6 & 3,927 & 29,194 & 31 & 43,913 & 69,548 & 56 & 67,260 & 91,418 & 81 & 88,124 & 130,734 \\
\hline 7 & 5,192 & 32,404 & 32 & 45,129 & 70,408 & 57 & 67,972 & 92,476 & 82 & 89,301 & 133,368 \\
\hline 8 & 6,721 & 35,238 & 33 & 46,344 & 71,255 & 58 & 68,684 & 93,563 & 83 & 90,553 & 136,136 \\
\hline 9 & 8,191 & 37,766 & 34 & 47,506 & 72,085 & 59 & 69,393 & 94,692 & 84 & 91,838 & 139,085 \\
\hline 10 & 10,057 & 40,056 & 35 & 48,643 & 72,925 & 60 & 70,092 & 95,824 & 85 & 93,201 & 142,203 \\
\hline 11 & 11,751 & 42,228 & 36 & 49,741 & 73,758 & 61 & 70,787 & 96,988 & 86 & 94,629 & 145,582 \\
\hline 12 & 13,571 & 44,284 & 37 & 50,813 & 74,593 & 62 & 71,496 & 98,181 & 87 & 96,151 & 149,247 \\
\hline 13 & 15,437 & 46,208 & 38 & 51,867 & 75,436 & 63 & 72,211 & 99,405 & 88 & 97,791 & 153,270 \\
\hline 14 & 17,301 & 48,045 & 39 & 52,890 & 76,268 & 64 & 72,926 & 100,658 & 89 & 99,534 & 157,740 \\
\hline 15 & 19,129 & 49,815 & 40 & 53,899 & 77,101 & 65 & 73,666 & 101,949 & 90 & 101,440 & 162,741 \\
\hline 16 & 20,978 & 51,540 & 41 & 54,902 & 77,944 & 66 & 74,411 & 103,259 & 91 & 103,538 & 168,563 \\
\hline 17 & 22,767 & 53,177 & 42 & 55,872 & 78,799 & 67 & 75,163 & 104,620 & 92 & 105,850 & 175,493 \\
\hline 18 & 24,528 & 54,749 & 43 & 56,814 & 79,651 & 68 & 75,936 & 106,006 & 93 & 108,507 & 183,796 \\
\hline 19 & 26,249 & 56,261 & 44 & 57,733 & 80,506 & 69 & 76,741 & 107,428 & 94 & 111,557 & 194,100 \\
\hline 20 & 27,947 & 57,718 & 45 & 58,626 & 81,363 & 70 & 77,550 & 108,914 & 95 & 115,196 & 207,522 \\
\hline 21 & 29,571 & 59,080 & 46 & 59,497 & 82,223 & 71 & 78,370 & 110,444 & 96 & 119,816 & 225,263 \\
\hline 22 & 31,192 & 60,374 & 47 & 60,351 & 83,077 & 72 & 79,217 & 112,067 & 97 & 125,994 & 249,978 \\
\hline 23 & 32,746 & 61,597 & 48 & 61,187 & 83,946 & 73 & 80,083 & 113,757 & 98 & 135,035 & 285,837 \\
\hline 24 & 34,253 & 62,732 & 49 & 61,990 & 84,815 & 74 & 80,979 & 115,550 & 99 & 150,762 & 349,437 \\
\hline 25 & 35,762 & 63,839 & 50 & 62,779 & 85,721 & 75 & 81,901 & 117,417 & 100 & 224,487 & 647,786 \\
\hline
\end{tabular}

Notes: This table shows the mean real income in 2017 Swiss Francs for fathers and children. 


\section{References}

Acciari, Paolo, Alberto Polo, and Giovanni L. Violante (2019). "And Yet It Moves": Intergenerational Mobility in Italy. Working Paper 25732. National Bureau of Economic Research. DOI: 10.3386/w25732.

Alvaredo, Facundo, Lucas Chancel, Thomas Piketty, Emmanuel Saez, and Gabriel Zucman (2017). "Global Inequality Dynamics: New Findings from WID.world". American Economic Review 107.5, pp. 404-409. DOI: 10.1257/aer.p20171095.

Bauer, Philipp (2006). The Intergenerational Transmission of Income in Switzerland A Comparison between Natives and Immigrants. WWZ Discussion Paper 06/01.

Bauer, Philipp and Regina T. Riphahn (Feb. 2007). "Heterogeneity in the intergenerational transmission of educational attainment: evidence from Switzerland on natives and second-generation immigrants". Journal of Population Economics 20.1, pp. 121148.

Bell, Alex, Raj Chetty, Xavier Jaravel, Neviana Petkova, and John Van Reenen (2019). "Who becomes an inventor in America? The importance of exposure to innovation". Quarterly Journal of Economics 134.2, pp. 647-713. DOI: 10.1093/qje/qjy028.

Black, Sandra E. and Paul J. Devereux (2011). "Recent Developments in Intergenerational Mobility". In: ed. by David Card and Orley Ashenfelter. Vol. 4. Handbook of Labor Economics. Elsevier. Chap. 16, pp. 1487-1541. DOI: https : //doi .org/10 . 1016 / S0169-7218(11)02414-2.

Chetty, Raj, Nathaniel Hendre, Patrick Kline, and Emmanuel Saez (Sept. 2014a). "Where is the land of Opportunity? The Geography of Intergenerational Mobility in the United States *". The Quarterly Journal of Economics 129.4, pp. 1553-1623. DOI: 10.1093/ qje/qju022.

Chetty, Raj, Nathaniel Hendren, Patrick Kline, Emmanuel Saez, and Nicholas Turner (2014b). "Is the United States Still a Land of Opportunity? Recent Trends in Intergenerational Mobility". The American Economic Review 104.5, pp. 141-147. 
Corak, Miles and Andrew Heisz (1999). "The intergenerational earnings and income mobility of Canadian men: Evidence from longitudinal income tax data". Journal of Human Resources, pp. 504-533.

Dahl, Molly W. and Thomas DeLeire (2008). "The Association between Children's Earnings and Fathers' Lifetime Earnings: Estimates Using Administrative Data”. University of Wisconsin-Madison.

Favre, Giacomin, Joël Floris, and Ulrich Woitek (2018). "Intergenerational Mobility in the 19th Century: Micro-Level Evidence from the City of Zurich Intergenerational Mobility in the 19 th Century Micro-Level Evidence from the City of Zurich".

Föllmi, Reto and Isabel Z Martínez (2017). "Die Verteilung von Einkommen und Vermögen in der Schweiz". UBS Center Public Paper.

Heidrich, Stefanie (Oct. 2017). "Intergenerational mobility in Sweden: a regional perspective". Journal of Population Economics 30.4, pp. 1241-1280.

Hertz, Tom (2006). "Understanding mobility in America". Center for American Progress Discussion Paper.

Mazumder, Bhashkar (2005). "Fortunate Sons: New Estimates of Intergenerational Mobility in the United States Using Social Security Earnings Data". The Review of Economics and Statistics 87(2), pp. 235-255.

Solon, Gary (1992). "Intergenerational Income Mobility in the United States". The American Economic Review 82.3, pp. 393-408.

- (1999). "Intergenerational mobility in the labor market". In: Handbook of labor economics. Vol. 3. Elsevier, pp. 1761-1800. 